\title{
Definiendo el concepto del Incremento Material del Riesgo en la relación de causalidad: ¿podría aplicarse en el Derecho peruano?
}

\author{
Ricardo Canepa Casillas ${ }^{(*)}$ \\ Abogado por la Universidad de Lima. \\ Máster en Derecho por la Universidad de Melbourne.
}

SUMARI0:

I. Introducción.

II. ¿Qué es el incremento material del riesgo?

1. La Regla General en el Derecho anglosajón para la causalidad fáctica: el examen but for.

2. Superando los vacíos probatorios: alternativas al examen but for.

3. Primera alternativa: Contribución material al daño.

3.1. Principales características de la contribución material al daño.

3.2. ¿Es la contribución material al daño realmente una excepción al examen but for?

3.3. ¿Esta aproximación se encuentra recogida en el ordenamiento jurídico peruano?

4. Segunda alternativa: Incremento material del riesgo.

4.1. Alcances generales.

4.2. Incremento material del riesgo: la "excepción Mcghee".

4.2.1. Wilsher.

4.2.2. McGhee.

4.2.3. Necesaria distinción de Fairchild.

4.2.4. Características de la excepción aplicada en McGhee, Barker y Sienkiewicz.

4.2.5. Principales críticas a la excepción McGhee.

4.3. Incremento material del riesgo: la "Excepción del Individuo Indeterminado".

4.3.1. El ámbito de aplicación.

4.3.2. La Excepción del Individuo Indeterminado y el problema de invertir la carga de la prueba.

4.3.3. Fairchild.

4.3.4. Clements.

4.3.5. Características de la Excepción del Individuo Indeterminado.

4.3.6. Diferencias con la causalidad probabilística.

4.3.7. Principales críticas y opinión.

III. La Excepción del Individuo Indeterminado en las legislaciones comparadas.

1. Alemania.

2. Los Países Bajos.

3. Argentina.

IV. ¿Podría aplicarse la Excepción del Individuo Indeterminado en el Derecho peruano?

1. Preámbulo: Principales características del nexo causal bajo la ley peruana.

2. La Excepción del Individuo Indeterminado no está positivizada.

3. Posible aplicación de la Excepción del Individuo Indeterminado en el Perú.

3.1. Aquellos casos que admiten la posibilidad de múltiples factores.

3.2. Casos que únicamente permiten la existencia de un solo factor.

4. La Excepción del Individuo Indeterminado debe aplicarse con cautela.

v. Conclusiones.

(*) Agradecimiento especial merece Jacques Didier D'Auriol Augusto, destacado alumno de la Facultad de Derecho de la Universidad de Lima, por su brillante e invaluable contribución a este trabajo. 


\title{
RESUMEN:
}

A través de este ensayo, el autor desarrolla la problemática de los vacíos probatorios que impiden establecer el nexo causal, particularmente cuando, si bien existe certeza de que el daño ha sido causado por una conducta negligente, es imposible determinar quién — o quiénes— dentro de un grupo que incrementó el riesgo de la producción del daño, efectivamente fue quien ocasiona el perjuicio. Como solución, el autor propone que una de las aplicaciones del concepto del "incremento material del riesgo", la "excepción del individuo indeterminado", puede implementarse en el ordenamiento jurídico peruano gracias a la flexibilidad que brinda la teoría de la causa adecuada. Sin embargo, para su aplicación debe observarse el desarrollo realizado por la doctrina y jurisprudencia anglosajona, incluyendo las lecciones aprendidas en el camino.

Palabras clave: Responsabilidad civil, incremento material del riesgo, contribución material al riesgo, vacío probatorio, causalidad, causa adecuada, causa necesaria, conducta negligente, Derecho anglosajón, but for, Wilsher, Bonnington, McGhee, Sienkiewicz, Barker, Fairchild, Cook, Summers, Litzinger, Clements.

\begin{abstract}
:
Through this essay, the author attacks the issues behind the evidentiary gaps that prevent the finding of a causal link between the damage and the wrongdoer, particularly when these evidentiary gaps preclude the claimant from proving who, within a group of persons who have increased the risk of damage, actually caused it. As a solution, the author proposes that the "multiple tortfeasor exception", which is an application of the "material increase in risk" developed in the common law, can be implemented in Peru thanks to the flexibility provided by the adequate cause (the Peruvian approach to causation). For these purposes, the lessons learned through the common law shall serve as guiding light.

Keywords: law of negligence, torts, liability, damages, material increase in risk, material contribution to harm, evidentiary gaps, causation, adequate cause, factual causation, common law, Peruvian law, but for, Wilsher, Bonnington, McGhee, Sienkiewicz, Barker, Fairchild, Cook, Summers, Litzinger, Clements.
\end{abstract}

\section{INTRODUCCIÓN}

Supongamos que una sociedad ficticia, la Compañía Minera Andina S.A. -en adelante, "CMA" - vierte de forma ilícita residuos tóxicos que contienen arsénico y mercurio en un río andino. Como resultado de ello, los habitantes de un pueblo situado a 10 kilómetros río abajo se envenenan con dichos químicos después de consumir el agua contaminada. En este caso, no hay duda de que los habitantes envenenados podrían reclamar sus respectivos daños contra la CMA. Eso está claro.

Ahora, imaginemos un escenario ligeramente diferente, en el que no sólo CMA, sino también la sociedad Minerales de la Sierra S.A. —en adelante, "MS" - vierten, también de manera ilícita, sustancialmente los mismos desechos tóxicos al mismo río. Lógicamente, en este escenario, los habitantes del referido pueblo son igualmente envenenados: algunos por agua contaminada por CMA, otros por agua contaminada por MS y el resto por agua contaminada por ambos. No obstante, a cada habitante le sería imposible determinar, con total certeza, si su envenenamiento fue causado únicamente por CMA, por MS o por ambas -en un cóctel de residuos-. ¿Podrían éstos obtener una indemnización? ¿A quién podrían demandar y cómo podrían superar estos problemas de la relación de causalidad?

El Código Civil peruano, a diferencia de otras legislaciones de Derecho Civil —como, por ejemplo, la alemana ${ }^{1}$ o la argentina ${ }^{2}-$, no da una respuesta clara a este problema. Sin embargo, a través de una de las aplicaciones del denominado "incremento material del riesgo", el Derecho

1. Ver el Bürgerliches Gesetzbuch-BGB —Código Civil alemán-, artículo 830(1).

2. Ver el Código Civil y Comercial argentino, artículos 1761 y 1762. 
anglosajón -el common law- ${ }^{3}$ parece haber encontrado una solución para que, a pesar de no existir una ley específica, se pueda compensar a los afectados.

En las siguientes líneas, luego de una breve revisión de las normas generales de la causalidad fáctica en el Derecho anglosajón, examinaré las dos posibles aplicaciones del incremento material del riesgo: la excepción McGhee y la excepción del individuo indeterminado y explicaré por qué esta última es, en mi opinión, la más coherente con los objetivos y principios propios de la responsabilidad civil.

Por último, argumentaré por qué la excepción del individuo indeterminado puede, y debe, cuidadosamente aplicarse en el Perú y por qué las actuales normas sobre la responsabilidad civil extracontractual contenidas en el Código Civil peruano nos lo permiten.

\section{II. ¿QUÉ ES EL INCREMENTO MATERIAL DEL RIESGO?}

Este concepto tiene diferentes denominaciones en distintas jurisdicciones. En Canadá, por ejemplo, la Corte Suprema ${ }^{4}$ lo ha denominado "contribución material al riesgo", mientras que en el Reino Unido y Australia se le ha denominado "incremento material del riesgo", tanto por la Cámara de los Lores ${ }^{5}$ como por el Tribunal Superior de Australia - High Court of Australia $-{ }^{6}$, respectivamente. A los efectos de este trabajo, adoptaré esta última denominación: incremento material del riesgo.

En las siguientes líneas, luego de una síntesis de las normas generales sobre la causalidad en el Derecho anglosajón, esbozaré las características más destacadas del incremento material del riesgo y sus diferentes aplicaciones: la excepción McGhee y la excepción del individuo indeterminado.

\section{La regla general en el Derecho anglosa- jón para la causalidad fáctica: el examen but for.}

Si bien no es parte del objeto de este artículo realizar un análisis sobre todos los presupuestos de la responsabilidad civil extracontractual en el Derecho anglosajón -en su variante de la law of negligence - ${ }^{7}$, por ahora basta con saber que un aspecto clave para el examen de la relación causal, que es un presupuesto de esta responsabilidad, es la causalidad fáctica ${ }^{8}$; esto es, probar que el demandado, en los hechos, causó o contribuyó materialmente al daño?.

3. A lo largo del presente trabajo, toda referencia al "Derecho anglosajón" —o common law — deberá entenderse realizada al propio del Reino Unido y, en menor extensión, al de Australia y Canadá; por lo que el presente artículo no incluye un análisis del desarrollo legislativo o jurisprudencial de los Estados Unidos de América.

4. Ver Clements vs. Clements [2012] 2 SCR 181.

5. Ver, por ejemplo, Fairchild vs. Glenhaven Funeral Services Ltd [2003] 1 AC 32.

6. Ver, por ejemplo, Strong vs. Woolworths Ltd (2012) 246 CLR 182.

7. Los cuales, a grandes rasgos, están compuestos por: un deber de cuidado, causalidad fáctica y jurídica, daño y negligencia. Asimismo, conviene aclarar que toda referencia que se haga al "régimen de responsabilidad civil extracontractual en el Derecho anglosajón" —o cualquier referencia similar-, deberá entenderse realizada exclusivamente a la "law of negligence", excluyendo otros supuestos que también pueden configurar dicha responsabilidad — torts—y que se rigen por reglas particulares; como, por ejemplo, la perturbación —nuisance-.

8. Denominada en el Perú causa natural o causa física. DE TRAZEGNIES GRANDA, Fernando. La Responsabilidad Extracontractual. Séptima edición. Lima: Fondo Editorial de la Pontificia Universidad Católica del Perú, 2001, pp. $306,358$.

9. LUNTZ, Harold; HAMBLY, David; y BURNS, Kylie. Torts: cases and commentary. Octava edición. Chatswood, NSW: LexisNexis Butterworths, 2017, p. 265. 
Para establecer la causalidad fáctica, se debe superar el examen but for.

El examen but for requiere que el tribunal respectivo responda a la siguiente pregunta: en un equilibrio de probabilidades, ¿la víctima hubiese sufrido igualmente el daño de no ser por la conducta negligente ${ }^{10}$ del demandado? ${ }^{11}$ Si la respuesta es afirmativa, es decir, si la víctima hubiese sufrido el daño de cualquier modo, independientemente de la participación del demandado, el examen but for fracasará y, por tanto, la demanda debería ser declarada infundada.

Como se puede apreciar, el examen but for no es otra cosa que una nueva expresión de la denominada "condición necesaria"12 o, lo que es lo mismo, la "condición sine qua non"13. El problema, sin embargo, es que este examen tiene al menos las siguientes tres limitaciones. En primer lugar, es un "criterio negativo de causa- lidad"14; es decir, que en lugar de explicar cuál fue la real causa del daño, se limita a descartar aquellos factores que no lo son. Así, por ejemplo, si se determina que la actividad realizada por el demandado no es una causa del accidente, entonces el examen but for ayudó a exonerar al demandado, pero no ayudó a determinar qué actividad sí fue la que ocasionó el daño.

En segundo lugar, puede dar falsos negativos. Este es el ejemplo de la "sobre determinación causal del daño"15: o sea, un daño que puede ser atribuible a más de una condición "suficiente"16; o, dicho de otro modo, un daño en el que cualquiera de dos o más causas hubiera bastado para producir la integridad del daño. El ejemplo clásico es el de las "dos balas, dos cazadores", consistente en dos cazadores, el Cazador 1 y el Cazador 2, que dispararon negligentemente en un bosque y ambas balas alcanzaron a un transeúnte que murió; demostrándose que cualquiera de las dos balas hubiera sido suficiente

10. Toda referencia aquí realizada a la "conducta negligente" del demandado, naturalmente incluirá cualquier supuesto de dolo por parte del mismo. Asimismo, en los casos que corresponda, la expresión "conducta negligente" deberá extenderse a omisiones igualmente dolosas o culposas y que sean dignas de tutela. De igual manera, cabe precisar que, si se quisiera adaptar el examen but for a la legislación peruana, éste también abarcaría supuestos de responsabilidad por actividad o uso de un bien riesgoso o peligroso, aunque para estos el examen se realizaría directamente respecto de la actividad y se prescindiría de la evaluación del factor de atribución.

11. STICKLEY, Amanda. Australian torts law. Cuarta edición. Chatswood, NSW: LexisNexis Butterworths, 2016, p. 297. Nótese que, en este trabajo, la pregunta del examen but for se está formulando de manera literal a como se hace en el Derecho anglosajón - "on a balance of probabilities, would the plaintiff have suffered the damage but for the defendant's negligence?"- - No obstante, existen maneras alternativas de preguntarse lo mismo, con palabras distintas, para determinar si la causa es necesaria. Una de ellas sería, por ejemplo, preguntarse: ¿el daño hubiese sido evitado si el demandado no hubiese cometido el acto negligente? En este caso, como se ha cambiado el sentido de la pregunta, la respuesta afirmativa — "sí, el daño se hubiese evitado" — es la que demuestra que el daño fue una causa sine qua non y, con ella, se aprobaría del examen but for.

12. Tan es así que este examen ha sido regulado expresamente en las normas de responsabilidad civil de la legislación australiana como la prueba de la "condición necesaria" — ver, por ejemplo, Civil Liability Act 2002, s 5D(1)(a); Wrongs Act 1958, s 51(1)(a) o Strong vs. Woolworths Ltd [2012] 246 CLR 182-.

13. Sobre un análisis más detallado de la condición sine qua non, ver, por ejemplo, a BELTRÁN, Jorge. "Estudios de la Relación Causal en la Responsabilidad Civil". En: Derecho y Sociedad. № 23, Lima, p. 262.

14. Ver, por ejemplo, Strong vs. Woolworths Ltd (2012) 246 CLR 182, p. 190 [18] —French CJ, Gummow, Crennan and Bell JJ-.

15. Review of the Law of Negligence (Final Report), p. 109 [7.26].

16. Ibíd. 
para causarle la muerte al transeúnte ${ }^{17}$. Por tanto, si se aplica el examen but for a ambos cazadores por separado, no podría quedar establecida la causalidad fáctica respecto de ninguno de ellos ${ }^{18}$. En nuestro ejemplo, si aplicamos este examen al Cazador 1 y nos preguntamos: iel transeúnte hubiese igualmente muerto de no ser por la actividad del Cazador 1? La respuesta será afirmativa y, por tanto, el Cazador 1 sería exonerado al no ser una causa necesaria del daño. Lo mismo sería cierto si realizamos la misma pregunta respecto del Cazador 2 por separado.

En tercer lugar, el examen but for no es un análisis adecuado cuando, para determinar la causalidad fáctica, se requiere de pruebas que no están disponibles en la ciencia, situación a la que se le denomina "vacío probatorio"19. Este tercer problema es el que nos ocupa en el presente trabajo y, para solucionarlo, el Derecho anglosajón ha desarrollado la aplicación de dos aproximaciones alternativas a esta causalidad: la contribución material al daño y el incremento material del riesgo.

\section{Superando los vacíos probatorios: alter- nativas al examen but for.}

Para el common law, el hecho de que el demandante no pueda probar exactamente cómo el demandado causó el daño, no quiere decir que, necesariamente, la víctima del daño fracasará en su demanda ya que "podría probarse la causalidad por una vía alternativa en circunstancias limitadas, si se trata de un caso excepcional"20.

Así, por ejemplo, en la legislación australiana existe una autorización expresa para que los tribunales puedan apartarse del examen but for cuando se encuentren ante un caso apropiado $^{21}$ o un caso excepcional ${ }^{22}$, siempre que esa desviación se ajuste a los principios establecidos de la tradición anglosajona y que el vacío probatorio sea el único factor que se esté interponiendo entre la víctima y la reparación.

Se suele mencionar que existen principalmente dos alternativas al examen but for para cubrir los vacíos probatorios: la contribución material al daño y el incremento material del riesgo.

\section{Primera alternativa: Contribución mate- rial al daño.}

\subsection{Principales características de la contribu- ción material al daño.}

La contribución material al daño es una aproximación a la causalidad fáctica que se aplica siempre que exista un daño ocasionado por una acumulación de causas $^{23}$; debiendo al menos una de ellas consistir en un actuar negligente. El otro requisito para la aplicación de esta figura es que el daño sea "indivisible" ${ }^{24}$ en el sentido de que no sea posible determinar la

17. STAPLETON, Jane. "Cause-in-fact and the scope of liability for consequences". En: Law Quarterly Review. Vol. July, N 119, 2003, p. 392.

18. Ibíd., p. 388.

19. "Evidentiary gap", en inglés —Ver: LEIMAN, Tania. "Anything but uniform: causation under civil liability legislation"—. Ver también: Precedent. Vol. 115, Marzo-Abril, 2013, p. 23-.

20. STICKLEY, Amanda. Op. Cit., p. 304.

21. Wrongs Act 1958, s 51(2).

22. Civil Liability Act 2002, s 5D(2).

23. Review of the Law of Negligence (Final Report), p. 109, párrafo [7.28].

24. Ibíd. 
proporción en que cada una de estas causas contribuyó al daño 25 .

En estos casos, la responsabilidad por la totalidad del daño puede imponerse a cada demandado que, por su actuar negligente, ha contribuido materialmente -es decir de una manera no insignificante- al resultado. ${ }^{26}$ El caso que mejor ejemplifica este concepto en los precedentes anglosajones es el de Bonnington Castings Ltd. vs. Wardlaw -en adelante, "Bonnington Castings" - ${ }^{27}$. En dicho caso, el demandante había desarrollado neumoconiosis - tratada en el caso como una enfermedad indivisible -28 a partir de una acumulación de partículas de polvo de sílice en el pulmón. Tales partículas provenían de tres fuentes, de las cuales sólo dos eran materiales significativos-. De esas dos, sólo una fuente era negligente: la indebida exposición al trabajador a la sílice que se producía de una máquina - un esmeril-. Aplicando el concepto de la contribución material al daño, la Cámara de los Lores llegó a la conclusión de que el demandado era responsable por la neumoconiosis que la víctima desarrolló, ello a pesar de que sólo una de las tres fuentes que ocasionaron dicha enfermedad había sido producto de una negligencia del empleador.

¿Cómo es que la contribución material al daño ayuda a llenar un vacío probatorio? Gracias a esta excepción, el demandante no tiene que probar que la conducta del demandado fue la única causa, o siquiera la principal, del daño; bastando con acreditar que ésta contribuyó materialmente a causar el daño. ${ }^{29}$ En Bonnington Castings, por ende, la víctima del daño no requería demostrar que la sílice proveniente del esmeril fue la única causa de la neumoconiosis, ni tampoco que fue la principal. Bastaba con acreditar que su exposición a dicha máquina fue significativa.

Esta conclusión, en mi opinión, es lógica y tiene coherencia con algunos principios fundamentales de la responsabilidad civil. Para explicar por qué, se me viene a la mente la popular frase "la gota que derramó el vaso". En efecto, graficando esta expresión, tenemos varios hechos y/o personas - llamémoslos "factores" - que van vertiendo distintas cantidades de agua en el vaso durante un cierto período. Cada factor llena una cantidad distinta en un momento diferente al otro; siendo algunos factores ilegales - por ejemplo, vertimientos ilegales-y otros no por ejemplo, agua vertida por actos de la naturaleza-. Ante un rebalse del agua, si quisiéramos establecer cuáles fueron las causas necesarias que llevaron a ello, será irrelevante saber quién puso la última gota que derramó el vaso o quién contribuyó exactamente con cuánto líquido.

Por el contrario, para efectos de la responsabilidad civil, sólo es relevante determinar quién o quiénes vertieron negligentemente una cantidad material ${ }^{30}$ de agua en el vaso, puesto que éste no se hubiese derramado si no fuera por la contribución material de aquellos factores negligentes. Ante la incertidumbre en torno a la proporción en la que contribuyó cada factor al derrame de agua, todos aquellos que fueron negligentes deberán responder solidariamente frente al demandado.

\footnotetext{
25. Strong vs. Woolworths Ltd (2012) 246 CLR 182, p. 194 [25].

26. LUNTZ, Harold; HAMBLY, David; y BURNS, Kylie. Op. Cit., p. 291.

27. Bonnington Castings Ltd vs. Wardlaw [1956] AC 613.

28. LUNTZ, Harold; HAMBLY, David; y BURNS, Kylie. Op. Cit. p. 290. Ver también BAILEY, S. H. “Causation in Negligence: What is a Material Contribution". En: Legal Studies. Vol. 30, N², 2010, p. 173.

29. BAILEY, S.H. Op. Cit., p. 174.

30. El Derecho anglosajón suele eliminar aquellas causas que solo contribuyeron de una manera ínfima o insignificante al daño.
} 


\section{2. ¿Es la contribución material al daño real- mente una excepción al examen but for?}

Por muy útil que sea la aplicación de la contribución material al daño, estoy de acuerdo con la corriente de opinión que sostiene que dicho concepto no es una real excepción al examen but for ya que, tomando como ejemplo a Bonnington Castings, "el polvo culpable", proveniente del esmeril, era una "condición necesaria" para producir la enfermedad pulmonar ${ }^{31}$. En otras palabras, si se sustrajera al esmeril, de los hechos, probablemente se hubiese evitado el daño; por lo que el perjuicio necesariamente se explica por el esmeril.

En este sentido, en el Derecho anglosajón, la parte excepcional de este planteamiento no se encuentra en el análisis de causalidad fáctica - puesto que es aplicable la regla general: el examen "but for"-, sino en la determinación de los daños en cabeza de cada autor. Así, en lugar de que cada autor pague únicamente la proporción que le corresponde por la contribución de su daño, el vacío probatorio, consistente justamente en la imposibilidad de determinar, o establecer al menos aproximadamente, la proporción en la que cada factor contribuyó al daño, obliga a la corte a responsabilizar solidariamente a todos los factores negligentes por el íntegro del daño. Por el contrario, según opina la doctrina especializada, si el daño no fuera indivisible - es decir, en caso de que sí se pudiese determinar la proporción en la contribución al daño de cada factor-, las cortes deberían ordenar a cada autor el pago únicamente de la proporción relativa a su daño. ${ }^{32}$

\section{3. ¿Esta aproximación se encuentra recogi- da en el ordenamiento jurídico peruano?}

Si bien la parte central de este trabajo consiste en determinar si es que la otra alternativa al examen but for - el incremento material del riesgo- es coherente con el Derecho peruano, resulta interesante saber hasta qué punto la contribución material al daño es compatible con las normas de responsabilidad civil contenidas en el Código Civil peruano. Considero que la respuesta depende del supuesto en el que nos encontremos.

Como punto de partida, la causa adecuada ${ }^{33}$ no exige que el hecho generador del daño sea la causa única ni la causa preponderante del perjuicio, por lo que una contribución material al daño podría, sujeto a la calificación del juzgador, calificar como la causa adecuada del daño. Desde ese punto de vista, la contribución material al daño parece ser compatible con el Código Civil peruano $y$, de encontrarse que una persona contribuyó materialmente al daño, dependiendo del caso concreto, podría considerase que la causalidad quedó establecida y esa persona será la responsable del íntegro del daño causado.

Por otro lado, de conformidad con el artículo 1983 del Código Civil peruano ${ }^{34}$, si la causa

31. DAVIES, Martin y MALKIN, Ian. Torts. Octava edición. New South Wales: LexisNexis Butterworths, 2018, p. 212.

32. BAILEY, S.H. Op. Cit., pp. 173-174, 180-184. En efecto, Bailey establece que la "decisión de la Cámara de los Lores no puede ser leída como si en todos los casos de una enfermedad acumulativa, o en todos los casos de neumoconiosis, el daño debe considerarse, por ley, como indivisible. No se discutió ni se llegó a ese punto". De igual manera, dicho autor citó casos en los que tribunales de menor jerarquía a la Cámara de los Lores — hoy la Corte Suprema del Reino Unido- han decidido prorratear los daños en proporción a la contribución aproximada del demandado; sólo para concluir que el prorrateo en los casos acumulativos es una práctica coherente con Bonnington Castings y que debe ser respaldada.

33. Para un análisis general sobre lo que se debe entender por la causa adecuada en el Perú, ver la sección IV siguiente.

34. Artículo 1983.- "Si varios son responsables del daño, responderán solidariamente. Empero, aquel que pagó la totalidad de la indemnización puede repetir contra los otros, correspondiendo al juez fijar la proporción según la gravedad de la falta de cada uno de los participantes. Cuando no sea posible discriminar el grado de responsabilidad de cada uno, la repartición se hará por partes iguales". 
adecuada del daño son múltiples autores, todos ellos responderán solidariamente frente a la víctima independientemente del grado de participación de cada quién en el perjuicio. Si el daño es divisible, en la distribución interna cada quién responderá proporcionalmente a su contribución al daño. Si fuera indivisible, la repartición interna se realizará en partes iguales.

Sin embargo, si la negligencia de uno o varios demandados tan solo hubiese concurrido con la imprudencia de la propia víctima ${ }^{35} \mathrm{y} / \mathrm{o}$, de manera discutible, con un supuesto de caso fortuito o fuerza mayor ${ }^{36}$, entonces el juzgador estará legalmente obligado a calcular el grado de incidencia de cualquiera de dichas causas concurrentes a efectos de reducir la indemnización. Si bien ello no representa mayor problema tratándose de daños divisibles, en cuyo caso la reducción se realizará en proporción a la contribución al daño de las causas concurrentes, resulta una tarea imposible tratándose de daños indivisibles. A pesar de ello, el juzgador no se encuentra autorizado a responsabilizar al demandado o demandados por el íntegro del daño; no siendo aplicable la figura de la contribución material al daño en este caso específico, debiendo el juzgador realizar la mencionada reducción "de acuerdo a las circunstancias", con la amplitud que esa expresión conlleva.

\section{Segunda alternativa: Incremento mate- rial del riesgo.}

\subsection{Alcances generales.}

El incremento material del riesgo, para el Dere- cho anglosajón, es otra aproximación a la causalidad fáctica que se usa como alternativa al tradicional examen but for. Para que aplique el incremento material del riesgo, el vacío probatorio debe consistir en que, si bien la ciencia sí ha podido determinar que el daño es consecuencia de un riesgo idéntico al que el demandado creó con su conducta, no es científicamente posible probar que él ocasionó, o contribuyó materialmente, al daño. Ello contrasta con la contribución material al daño, figura en la que sí existe certeza de que el demandado contribuyó a que el perjuicio se ocasione, pero no se sabe en qué medida o proporción.

Otra diferencia se encuentra en que, mientras que típicamente la contribución material al daño es aplicable en casos en que el perjuicio se genera gracias a una acumulación progresiva de factores durante el tiempo, en el incremento material del riesgo el daño puede ser causado por un solo factor, o por un conjunto de factores, que son capaces de configurar el daño en un solo instante, sin que se requiera una sucesión a lo largo del tiempo de los mismos.

Si bien dichas distinciones pueden ser muy difíciles de encontrar en los hechos y existen infinidad de casos en los que la elección entre estas alternativas puede parecer una tarea imposible, en las siguientes líneas presentaré algunos de los casos más emblemáticos en los que la jurisprudencia anglosajona ha recurrido al incremento material del riesgo para superar el vacío probatorio correspondiente. Como intentaré explicar a continuación, el incremento material al riesgo ha sido utilizado por las cortes

35. Código Civil peruano. Artículo 1972.- "En los casos del artículo 1970, el autor no está obligado a la reparación cuando el daño fue consecuencia de caso fortuito o fuerza mayor, de hecho determinante de tercero o de la imprudencia de quien padece el daño".

Artículo 1973.- "Si la imprudencia sólo hubiere concurrido en la producción del daño, la indemnización será reducida por el juez, según las circunstancias."

36. Si bien el artículo 1973 del Código Civil peruano no lo enuncia expresamente, considero que la misma lógica —es decir la reducción de la indemnización - debería aplicar para cuando el caso fortuito o fuerza mayor concurre con la negligencia del demandado, idea que es compartida en la doctrina nacional —En: DE TRAZEGNIES GRANDA, Fernando. Op. Cit., p. 383-. El reto, sin embargo, está en superar la literalidad de la norma cuando el artículo 1973 del Código Civil peruano parece ser una norma de excepción y, en aplicación del artículo IV del Título Preliminar de dicho código, no se podría aplicar analógicamente para los casos en que la causa concurrente es un caso fortuito o fuerza mayor. 
del common law en dos supuestos diferenciables entre sí - dos subtipos de esta aproximación-: la "excepción McGhee" y la "excepción del individuo indeterminado". En mi opinión, la primera de ellas presenta incompatibilidades importantes respecto del examen but for, mientras que la segunda resulta más coherente con dicho test y con los principios que inspiran el régimen de responsabilidad extracontractual en el common law.

\subsection{Incremento material del riesgo: la "ex- cepción McGhee".}

La presente excepción ha sido desarrollada íntegramente por la jurisprudencia anglosajona a través de una serie de precedentes, los que resumiré a continuación. Analizados los mismos, presentaré cuáles son las características de esta excepción y en qué consisten sus principales críticas.

\subsubsection{Wilsher.}

En el caso Wilsher vs. Essex Area Health Authority —en adelante, "Wilsher"— ${ }^{37}$, el demandante era un bebé recién nacido que había sido negligentemente expuesto a una dosis de oxígeno más alta de lo normal luego de su prematuro nacimiento. El problema fue que el demandante posteriormente quedó ciego y no era científicamente posible determinar si la causa de la ceguera fue la alta exposición al oxígeno o no, puesto que había al menos cuatro otros factores que por sí solos pudieron haber causado la ceguera - condiciones médicas comunes en los casos de nacimiento prematuro y con las que la víctima había nacido-.

En tal sentido, si bien la alta exposición al oxígeno -único factor negligente del total de posibles causas - había incrementado el riesgo de ceguera, la corte determinó que no se había establecido un nexo causal dado que, en el balance de probabilidades, la referida conducta negligente no era la causa más probable de la ceguera; por lo que la Cámara de los Lores desestimó la demanda. En otras palabras, el examen but for no fue superado ya que, a criterio de los juzgadores, no se había acreditado que -en un balance de probabilidades - la alta dosis de oxígeno haya sido una causa necesaria de la enfermedad. Esta decisión fue posteriormente revisada y aprobada por la misma Cámara de los Lores en el caso Fairchild ${ }^{38}$ —en adelante, "Fairchild", que se relatará más adelante-, concluyéndose que, como regla general, no es suficiente con acreditar que el demandado incrementó el riesgo del daño para establecer la causalidad.

\subsubsection{McGhee.}

Un enfoque completamente diferente $-\mathrm{y}$ controvertido - ${ }^{39}$ fue tomado en el caso McGhee vs. National Coal Board -en adelante, "McGhee" ${ }^{40}$. En este proceso, el demandante desarrolló dermatitis como resultado de haber estado expuesto a polvo de arcilla mientras trabajaba en una fábrica de ladrillos.

El demandante pudo demostrar tres hechos: a) que la dermatitis era una consecuencia del polvo de ladrillo; b) que el demandado no le proporcionó duchas para poder limpiarse el polvo de la piel al finalizar la jornada laboral; $y, c)$ que la falta de duchas "aumentaba materialmente el riesgo" de contraer la enfermedad.

Sin embargo, la víctima no logró acreditar que su exposición al polvo era producto de una conducta negligente debido a que, en el proceso quedó demostrado que la fuente de exposición contaba con todas las medidas de cuidado, se-

37. Wilsher vs. Essex Area Health Authority [1988] AC 1074.

38. Fairchild vs. Glenhaven Funeral Services Ltd [2003] 1 AC 32.

39. DAVIES, Martin y MALKIN, Ian. Op. Cit., p. 237.

40. McGhee vs. National Coal Board [1972] 3 All ER 1008. 
gún ley. Por el contrario, la negligencia se limitó a la ausencia de duchas en el centro de trabajo. Aún más importante que lo anterior, la víctima no probó que, en el balance de probabilidades, la instalación de las duchas en el centro de trabajo hubiese prevenido la dermatitis.

En otras palabras, a pesar de que el demandante probó que el demandado había "aumentado materialmente el riesgo" de contraer la dermatitis debido a la ausencia de duchas, no quedó acreditado que el daño probablemente se hubiese evitado de no ser por la negligencia del demandado, fracasando así el examen but fort ${ }^{11}$. De este modo, no se estableció que la ausencia de las duchas fue una causa necesaria del daño.

Curiosamente, a diferencia de la decisión en Wilsher ${ }^{42}$, en el presente caso la Cámara de los
Lores, por unanimidad -aunque con diferentes razones- ${ }^{43}$, falló a favor del demandante. Efectivamente, en McGhee, la Cámara de los Lores estableció un nuevo principio ${ }^{44}$ a través del cual, de manera incompatible con el examen but for, "aumentar el riesgo de que se produzca la enfermedad es suficiente para establecer la relación causal ${ }^{\prime \prime 5}$ siempre que se cumplan algunos requisitos básicos; siendo uno de ellos, por ejemplo, que mientras mayor haya sido la exposición al riesgo, mayor es la posibilidad de que la víctima sufra el daño ${ }^{46}$.

Este precedente ha sido aplicado en casos posteriores, como Barker vs. Corus UK Ltd -en adelante, "Barker" - ${ }^{47}$ y las acciones acumuladas decididas en Sienkiewicz vs. Greif UK Ltd —en adelante, "Sienkiewicz" — ${ }^{48}$, que son relativamente recientes y que han suscitado la misma controversia.

41. Fairchild, párrafo [21] — Lord Bingham-.

42. En un fallo posterior, la Cámara de los Lores explicó que los hechos de McGhee son distinguibles de los que suscitaron la controversia en Wilsher. Si bien en el primero de los nombrados el empleador también incrementó el riesgo de causar un daño, a diferencia de lo sucedido en Wilsher, en McGhee hay dos aspectos clave que sí quedaron demostrados: a) que el polvo de arcilla —y no otro factor- fue lo que causó el daño; y, b) que la negligencia del empleador estaba relacionada con dicho factor — las duchas hubieran removido el polvo de arcilla-. —En: Fairchild vs. Glenhaven Funeral Services Ltd [2003] 1 AC 32, párrafo [22] (Lord Bingham)—.

43. LUNTZ, Harold; HAMBLY, David; y BURNS, Kylie. Op. Cit. p. 286.

44. En un fallo posterior, Lord Rodger reconoció que "McGhee indudablemente contribuyó al desarrollo de la ley en lo que concierne a la relación de causalidad." —En: Fairchild, párrafo [154]—.

45. Ibíd., párrafo [65] —Lord Hoffmann-.

46. Ibíd., párrafos. [61], [64], [67] —Lord Hoffmann, Lord Rodger concurriendo en el párrafo [154]—.

47. Barker vs. Corus UK Ltd [2006] 2 AC 572. En este caso, el demandante contrajo mesotelioma luego de haber sido expuesto a tres fuentes de asbesto: dos de ellas atribuibles a la negligencia del demandado y otra atribuible a la propia negligencia del demandante — mientras trabajaba de manera independiente- - A pesar de que la Cámara de los Lores no pudo determinar que, en el balance de probabilidades, el demandado había causado el daño, la demanda fue declarada fundada, aunque solo se ordenó al demandado pagar la proporción de los daños correspondiente a su conducta negligente —En: LALENG, Per. "Sienkiewicz v Greif (UK) Ltd and Willmore v Knowsley Metropolitan Borough Council: A Material Contribution to Uncertainty Case". En: Modern Law Review. Vol. $74, \mathrm{~N}^{\circ} 5,2011$, p. 781-.

Curiosamente, este último extremo generó un cambio legislativo de la sentencia en cuestión de semanas; en virtud del cual, en el Reino Unido, ya no es posible reducir la indemnización en casos de mesotelioma aun cuando la conducta del demandado concurrió con otros factores, incluyendo la negligencia de la propia víctima —En: Ídem-.

48. Sienkiewicz v Greif UK Ltd [2011] UKSC 10. En este caso, se encontró que el demandado había expuesto al demandante a un bajo nivel de asbesto, pero ese nivel no era suficiente para calificar esta exposición como mínima - la exposición, por tanto, era material-. A raíz de ello, el demandante obtuvo una indemnización. 
Con este precedente, la Cámara de los Lores decidió apartarse por completo del examen but for puesto que, a pesar de la falta de pruebas que apuntaran a que la negligencia del demandado había causado o contribuido materialmente al daño, se decidió otorgar una compensación al demandante.

Para graficar por qué esta decisión está tan distanciada del examen but for, los hechos de Sienkiewicz pueden resultar ilustrativos. En este caso, las víctimas demostraron haber desarrollado mesotelioma - un tipo específico de cáncer que ataca órganos internos, siendo el de mayor frecuencia los pulmones- y la Cámara de los Lores determinó que esta enfermedad fue causada por el asbesto inhalado por los demandantes. No obstante, también se estableció que solo una pequeña parte de la exposición al asbesto había sido causada por la negligencia de los demandados. De hecho, la Cámara de los Lores determinó la siguiente proporción en la exposición al asbesto:

\begin{tabular}{|lc|}
\hline Fuente & Porcentaje \\
\hline $\begin{array}{l}\text { Exposición ambiental } \\
\text { en un día normal } \\
\text {-causas ambientales_- }\end{array}$ & $\mathbf{8 4 . 7 5 \%}$ \\
\hline $\begin{array}{l}\text { Exposición atribuible } \\
\text { a la negligencia de los } \\
\text { demandados en una } \\
\text { jornada laboral }\end{array}$ & $15.25 \%$ \\
\hline Total & $\mathbf{1 0 0 \%}$ \\
\hline
\end{tabular}

Lo anterior se distribuye gráficamente de la siguiente manera:

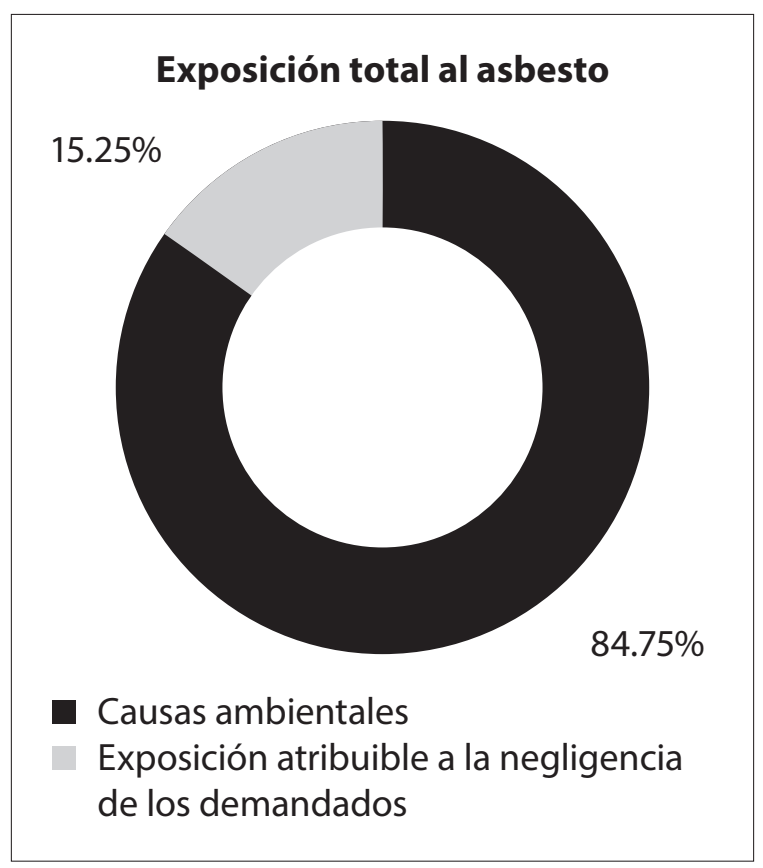

Así las cosas, y asumiendo que el mesotelioma puede contraerse "por una sola fibra, unas pocas fibras o muchas fibras de asbesto", y no obligatoriamente mediante una acumulación de fibras ${ }^{49}$, no es posible determinar que, en el balance de probabilidades, los demandantes desarrollaron la enfermedad a causa de la exposición negligente a cargo de los demandados. Ante la pregunta: ¿Los demandantes probablemente hubiesen contraído mesotelioma incluso si no hubiesen inhalado el asbesto al que fueron expuestos por los demandados? La respuesta — en base a la evidencia actuada en este caso- debe ser afirmativa - 84.75\% > $15.25 \%-y$, por ende, la exposición negligente no puede considerarse una causa necesaria del daño, fracasando así el examen but for.

En virtud de lo anterior, al fallar a favor del demandante, la Cámara de los Lores - denominada la Corte Suprema del Reino Unido al mo-

49. Fairchild, párrafo. [7] (Lord Bingham). Si bien en Sienkiewicz se pone en tela de juicio esta afirmación, no se llegó a aceptar la teoría de que esta enfermedad sea siempre producto de una acumulación del asbesto —En: Sienkiewicz, párrafo [102], p. 59 (Lord Phillips)_. En caso la ciencia demuestre que efectivamente una sola fibra del asbesto no puede causar mesotelioma y que necesariamente se requiere de una acumulación de las mismas, entonces los casos de mesotelioma se deberán resolver bajo las reglas de la Contribución Material al Daño. 
mento en que se decidió Sienkiewicz y hasta el día de hoy - ha decidido crear una excepción al examen "but for" antes de negar resarcimiento a la víctima, lo cual - como se detalla más adelante- no sólo ha sido objeto de críticas por la doctrina especializada, sino que parece haber despertado en la misma Corte Suprema del Reino Unido una sensación de arrepentimiento.

\subsubsection{Necesaria distinción de Fairchild.}

La decisión tomada en McGhee fue detalladamente revisada en Fairchild, un caso en el que los demandantes habían contraído mesotelioma después de que tres distintos empleadores los habían negligentemente expuesto al asbesto durante largos períodos.

Si bien la Cámara de los Lores había llegado a la conclusión de que, en el balance de probabilidades, la enfermedad era una consecuencia de una exposición negligente al asbesto, no se sabía con certeza cuál de los empleadores, o qué combinación de ellos, había expuesto a cada víctima a la fibra -o las fibras - de asbesto que en los hechos causó, o causaron, el mesotelioma en cada caso. A pesar de ello, la Cámara de los Lores falló en favor de las víctimas, y obligó a los demandados a pagar solidariamente el íntegro de los daños.

Toda vez que en Fairchild la Cámara de los Lores había descartado que el mesotelioma de cada una de las víctimas haya sido causado por factores externos al control de los demandados, sólo quedaba una pregunta por responder: ¿quién de los tres empleadores, o qué combinación de ellos, era el responsable de cada daño? Como se puede apreciar, a diferencia de Wilsher, McGhee, Barker y Sienkiewicz, en Fairchild el vacío probatorio no consiste en determinar "si es que" algún demandado es el responsable, sino en probar "quién" de ellos debe responder.

En tal sentido, considero que Fairchild no pertenece al mismo grupo que los casos antes citados y, por tanto, lo desarrollaré con más detalle en la sección II.4.3.3 siguiente.

\subsubsection{Características de la excepción aplica- da en McGhee, Barker y Sienkiewicz.}

¿Qué tienen en común McGhee, Barker y Sienkiewicz? En primer lugar, en cada caso el demandado había negligentemente creado al menos una fuente de riesgo que incrementaba la probabilidad del daño - en adelante, las "Fuentes Negligentes"-. No obstante, igualmente existía al menos una fuente de riesgo que también incrementaba las chances del daño, pero que no era atribuible a la negligencia del demandado; incluyéndose, dentro de estas fuentes, factores naturales, actividades ejercidas negligentemente por la propia víctima o fuentes que, si bien fueron creadas por el demandado, éste operó diligentemente -en adelante, las "Fuentes No Atribuibles" -

En segundo lugar, en cada caso el daño fue causado por un agente o factor de la misma naturaleza al creado por la Fuente Negligente. Por ejemplo, en McGhee, al no proporcionar duchas, el demandado había incrementado negligentemente el riesgo de que la víctima desarrolle dermatitis por su exposición al polvo de ladrillo y, en efecto, el polvo de ladrillo causó la dermatitis.

En tercer lugar, sin embargo, en el balance de probabilidades, lo que causó el daño no fue la Fuente Negligente, sino una de las Fuentes No Atribuibles; por lo que el examen but for fracasó. En el mismo ejemplo de McGhee, lo más probable es que el daño no se ocasionó por el actuar negligente del demandado y hubiera igualmente sucedido incluso si se proporcionaban las duchas, por lo que la ausencia de las mismas no fue una condición necesaria para el daño.

En virtud de la "doctrina del precedente" que rige al Derecho anglosajón, en cada caso en que se cumplan los tres elementos antes mencionados, las cortes y tribunales del Reino Unido estarán obligados a aplicar una excepción a las reglas de causalidad fáctica siempre que el demandante demuestre que: a) sufrió un daño; b) el factor o agente que causó el daño está perfectamente identificado y; c) el demandado incrementó materialmente el riesgo de causar el daño al haber 
expuesto negligentemente a la víctima al factor o agente a que se refiere el ítem $b$ ) anterior.

Si bien esta excepción al examen but for -en adelante, la "Excepción McGhee"-, anecdóticamente, en la literatura del Derecho anglosajón, a esta excepción se le denomina la "excepción Fairchild"; lo cual considero que es una inexactitud no solo porque los hechos de Fairchild son perfectamente distinguibles de los de McGhee - por lo que su excepción tiene un ámbito de aplicación distinto-, sino también porque Fairchild, en mi opinión, es un fallo mucho más coherente con el examen but for.

\subsubsection{Principales críticas a la excepción Mc- Ghee.}

Las razones por la que la Cámara de los Lores - hoy Corte Suprema del Reino Unido-decidió crear la excepción McGhee parecen haber estado influenciadas por un sentimiento de "querer hacer justicia" en un caso particular a pesar de que las normas vigentes de causalidad no apoyaban esa decisión. El problema de ello, sobre todo con reglas tan rígidas como las de la "doctrina del precedente", es que las excepciones se pueden "salir de las manos" cuando no guardan mayor coherencia con los principios subyacentes al derecho en cuestión; y éste parece ser el caso.

En efecto, la principal desventaja de apartarse del examen but for es que termina resultando irrelevante si es que el demandado causó o no el daño, obligándosele a pagar una compensación por el simple incremento de un riesgo ${ }^{50}$; contraviniéndose así un principio básico de la responsabilidad civil según el cual, "sin daño no hay resarcimiento". Esta misma crítica ha sido compartida por la doctrina que comenta el Derecho anglosajón, según la cual a través de la excepción McGhee:

"la Cámara de los Lores creó un nuevo supuesto de responsabilidad civil extracontractual consistente en incrementar el riesgo, donde el 'daño' que da lugar a la indemnización debe reconceptualizarse como un 'riesgo de causar daño' en vez del daño físico efectivamente sufrido por la víctima". ${ }^{51}$

Lo anterior ha ocasionado que la propia Corte Suprema del Reino Unido se cuestione la pertinencia de mantener vigente la excepción McGhee, llegando a afirmar que esta figura "crea muchos conflictos" y que una de las razones por las cuales no se deja sin efectos es por la sospecha de que, si lo hiciesen, el parlamento británico pronto revertiría la situación, trayendo de vuelta la aplicación de esta excepción ${ }^{52}$. Ello ha llevado a la referida Corte Suprema a intentar limitar el campo de acción de la excepción McGhee únicamente a casos de mesotelioma desarrollados por trabajadores ${ }^{53}$ puesto que la Corte Suprema del Reino Unido parece estar convencida de que todo caso de mesotelioma es precedido de una exposición al asbesto y que todo empleador negligente debe compensar íntegramente a la víctima por la exposición a dichas partículas. ${ }^{54}$

50. Lo cual acerca a la excepción McGhee a figuras como la "causalidad probabilística" —que se describirá brevemente en la sección II.4.3.6 siguiente-, que hasta cierto punto prescinden del daño como un presupuesto de la indemnización.

51. LALENG, Per. Op. Cit., p. 781.

52. Sienkiewicz, párrafo [167] —Lady Hale-

53. Con lo cual, irónicamente, casos como el de McGhee no estarían comprendidos dentro de la excepción McGhee.

54. Sienkiewicz., párrafo [1] —Lord Phillip—. Aquí, por ejemplo, Lord Phillip declaró que "en la mayoría, y posiblemente en todos los casos, [el mesotelioma] es causado por la inhalación de fibras de asbesto", Lady Hale agregando que si bien "se sabe desde hace mucho tiempo que el asbesto es una sustancia peligrosa —además de útil-, los empleadores se han hecho de la vista gorda ante esos peligros por mucho más tiempo del que su conocimiento lo permitía, y el mesotelioma es una enfermedad terrible" —En: Ibíd., párrafo [167]—. 
De manera concordante con el intento por limitar el campo de acción de esta excepción, las cortes y tribunales de menor jerarquía en el Reino Unido han venido aplicando la excepción McGhee exclusivamente en los referidos casos de mesotelioma desarrollados en el ámbito ocupacional y últimamente han negado resarcimiento en diversos otros casos que, si bien en principio podrían reunir los requisitos expuestos en la sección II.4.2.4 precedente, tienen por objeto otras enfermedades, como estrés postraumático, cáncer al pulmón, infecciones diversas, adicción al juego y apuesta y daño derivado de radiación. ${ }^{55}$

\subsection{Incremento material del riesgo: la "Excep- ción del Individuo Indeterminado".}

\subsubsection{El ámbito de aplicación.}

Esta excepción consiste en establecer una causalidad fáctica entre el daño y un grupo de personas cuyo actuar negligente incrementó el riesgo de que se materialice el daño —en adelante, el "Grupo Negligente" - a pesar de que exista un vacío probatorio que científicamente impida determinar exactamente qué individuo —o individuos- del Grupo Negligente causó o causaron el daño —en adelante, la "Excepción del Individuo Indeterminado"—.

El ejemplo clásico para explicar la Excepción del Individuo Indeterminado es el de "una bala, dos cazadores"56, litigado en muchas jurisdicciones; entre ellas, Canadá en el caso Cook vs. Lewis —en adelante, "Cook" - 57, Estados Unidos de América en el caso Summers vs. Tice —en adelante, "Summers"- ${ }^{58}$ y Francia en el caso Litzinger ${ }^{59}$, —en adelante, "Litzinger"—.
Como su nombre lo indica, el ejemplo consiste en dos cazadores, el Cazador 1 y el Cazador 2, que disparan negligentemente y de manera simultánea en el bosque: por ejemplo, tratando de cazar a un ciervo, en un área tupida, sin tener la certeza de los elementos que se encuentran alrededor del objetivo. Sin embargo, ambos cazadores fallan y ninguno impacta al ciervo, pero una de las dos balas impacta a un transeúnte que se encontraba atrás del objetivo. El problema en estos casos es que el "vacío probatorio" impide determinar científicamente cuál de los dos cazadores disparó la "bala culpable". Así las cosas, si bien se sabe que una de las balas disparadas impactó al transeúnte, no es posible saber cuál de los dos cazadores la disparó, por lo que no se sabe quién de los dos fue la causa fáctica del accidente.

La Excepción del Individuo Indeterminado, al igual que la excepción McGhee aplica en casos en que: a) si analizamos a cada uno de los posibles causantes del daño por separado, existe un vacío probatorio que impide determinar si dicho demandado causó, o contribuyó materialmente, a causar el daño; $y, b$ ) existe un daño que puede haber sido causado por un solo factor y no necesariamente una acumulación de factores.

Sin embargo, a diferencia de la excepción McGhee, en la Excepción del Individuo Indeterminado sí existe la certeza de que al menos una conducta negligente causó el daño, pero es científicamente imposible determinar cuál -o cuáles-, de todas las causas negligentes, es la que efectivamente lo ocasionó. Finalmente, la Excepción del Individuo Indeterminado debe distinguirse de Wilsher dado que en la referida

55. LALENG, Per. Op. Cit., p. 787.

56. STAPLETON, Jane. Op. Cit., p. 396.

57. Cook vs. Lewis [1951] SCR 830.

58. Summers vs. Tice 33 Cal 2 d $80-1948-$

59. Litzinger, Cour de cassation [Corte de Casación], 1036, 5 de junio del 1957, Jur 493. 
excepción, el daño es ocasionado necesariamente por la misma actividad que la realizada por los demandados.

Para explicar por qué esta variante del incremento material del riesgo constituye, al menos en principio, una excepción al examen but for, es conveniente recurrir de nuevo al ejemplo de "una bala, dos cazadores", en cuyo caso este examen fracasaría si se aplicase a cada cazador individualmente. En efecto, dado que cada cazador tiene $50 \%$ de probabilidades de haber cometido el daño, no se puede afirmar con certeza, que - por ejemplo- el Cazador 1 fue una causa necesaria del perjuicio o, dicho de otro modo, que el daño se hubiera evitado si quitamos al Cazador 1 de la ecuación. El mismo resultado se obtendría al analizar la conducta del Cazador 2 aisladamente.

\subsubsection{La Excepción del Individuo Indetermi- nado y el problema de invertir la carga de la prueba.}

La solución que propone esta excepción es hacer responsables a todos los miembros del Grupo Negligente -en el ejemplo anterior, a ambos cazadores-, siendo el único debate si todos responden solidariamente o si cada quién responde en proporción al riesgo creado, aunque la aplicación tradicional sería la de responsabilizar a todos solidariamente, siendo así como se resolvieron todos los casos antes mencionados de "una bala, dos cazadores": Cook, Summers y Litzinger. Para ser justos, no obstante, debo indicar que ni la Corte Suprema de Canadá, ni la Corte Suprema de California, ni la Corte de Casación francesa resolvieron los respectivos casos aplicando expresamente el concepto del Incremento Material del Riesgo. En Cook ${ }^{60}$ y Summer ${ }^{61}$, los tribunales norteamericanos resolvieron formalmente las controversias trasladando la carga de la prueba a los demandados; haciendo que cada cazador pruebe que él no fue el que causó el daño, lo cual ninguno de ellos finalmente logró. ${ }^{62}$

Sin embargo, invertir la carga de la prueba en la relación de causalidad implica, para efectos prácticos, obligar a los demandados a pagar la indemnización puesto que justamente existe una imposibilidad científica de que cada cazador demuestre que él no fue el que disparó la "bala culpable" o que sí fue el otro cazador quien la disparó. En ese sentido, se ha afirmado, acertadamente, que invertir la carga de la prueba "no es deseable porque no soluciona directamente el problema del vacío probatorio, sino que la ocul$t^{\prime \prime 63}$, lo que finalmente condujo a que la legislación australiana sobre responsabilidad civil prohibiera expresamente a los tribunales invertir la carga de la prueba con respecto a la relación de causalidad $^{64}$.

Habiendo determinado cómo se ha abordado este problema en casos pasados, conviene revisar dos casos relativamente más recientes en los que dos diferentes jurisdicciones, la británica y la canadiense, han evaluado - e incluso aplicado- la Excepción del Individuo Indeterminado en contextos diferentes a los del caso de "una bala, dos cazadores".

\subsubsection{Fairchild.}

Si bien la esencia del caso Fairchild fue descrita en la sección II.4.2.3 anterior, resulta necesario volver a este caso y dar más detalles sobre el mismo.

60. Cook, p. 833 -Rand J-.

61. Summers, pp. 84-85 - Carter J-.

62. En cambio, en Litzinger, la Corte de Casación francesa adoptó un enfoque más abstracto al declarar que el accidente no era producto de una bala, sino de una acción concertada de los cazadores.

63. Review of the Law of Negligence (Final Report), p. 111, párrafo [7.34].

64. Ver, por ejemplo, Wrongs Act 1958, s 52. 
Fairchild involucró a tres demandantes, el Señor Fairchild, el Señor Fox y el Señor Matthews, todos los cuales desarrollaron mesotelioma como consecuencia de haber sido negligentemente expuestos al asbesto por múltiples empleadores. En cada uno de los casos, la Cámara de los Lores estaba convencida de que la exposición negligente al asbesto era, en el balance de probabilidades, la causa de la enfermedad, pero resultaba científicamente imposible determinar cuál de los varios empleadores, o qué combinación entre ellos, causó la exposición a la fibra - o las fibras - de asbesto que efectivamente causó o causaron la enfermedad, debiendo recordarse que - -según las pruebas científicas actuadas en el proceso- - una sola fibra de asbesto era capaz de generar la enfermedad, pero también lo era un conjunto de fibras.

La decisión en Fairchild fue expuesta por Lord Bingham, quien sentó el siguiente precedente con relación al incremento material del riesgo.

Así, en todos los casos en que se cumplan los siguientes supuestos:

a) El demandante " $\mathrm{C}$ " fue trabajador en diferentes momentos y por diferentes periodos de dos empleadores distintos "A y B";

b) A y $B$ sabían que la inhalación del asbesto podía conducir al mesotelioma y tenían el deber de cuidar que $\mathrm{C}$ no los inhalase;

c) A y B incumplieron ese deber; d) C sufre de mesotelioma;

e) Cualquier otra causa — diferente a la exposición negligente al asbesto por parte de $\mathrm{A}$ y $\mathrm{B}$ - del mesotelioma de $\mathrm{C}$ ha sido descartada; pero,

f) C no puede probar, en el balance de probabilidades, que su mesotelioma fue el resultado de la inhalación del asbesto durante su tiempo de trabajo en los locales de A, o durante su empleo por $B$, o un resultado del tiempo en ambos empleos.

C tiene derecho a obtener una reparación civil tanto de $\mathrm{A}$ como de $\mathrm{B}^{65}$.

Cabe añadir que, si bien Lord Bingham limitó expresamente este asunto a los casos que reúnan los requisitos a) a f) anteriores, no negó la posibilidad de que en el futuro se presenten casos similares que puedan merecer el mismo desarrollo por analogía. ${ }^{66}$

\subsubsection{Clements.}

El caso Clements ${ }^{67}$ —en adelante, "Clements" no fue decidido sobre la base de la figura del incremento material del riesgo, por lo que no es necesario un detalle minucioso de sus hechos. ${ }^{68}$ No obstante, en la parte considerativa de Clements ${ }^{69}$, la Corte Suprema de Canadá evaluó y describió en detalle cuáles son los rasgos propios del incremento material del riesgo, en su variante de la Excepción del Individuo Indeterminado.

65. Fairchild, párrafo [2], [34] —Lord Bingham-.

66. Ibíd., párrafo. [34] —Lord Bingham —. Esta misma restricción fue compartida por Lord Hoffmann, quien además de aconsejar cautela en la aplicación de lo decidido en Fairchild, declaró expresamente que cualquier otro caso distinto al de mesotelioma debía ser examinado a la luz de los hechos particulares de esa controversia —En: Ibíd., párrafo [73] (Lord Hoffmann)-.

67. Ver Clements vs. Clements [2012] 2 SCR 181.

68. Basta saber que, según las pruebas, no se pudo determinar si el accidente de moto había sido causado por la negligencia del conductor — exceso de velocidad — o si habría ocurrido por otra causa — un clavo en el neumático trasero-.

69. Clements, párrafos [17]-[46] —McLachlin CJ-. 
En síntesis, en Clements se estableció que la Excepción del Individuo Indeterminado debía reunir características similares a las explicadas por Lord Bingham en Fairchild; agregando que, como su nombre lo indica, ésta constituye una excepción al examen but for que debe aplicarse en los casos en que la víctima - por factores externos a su control - se enfrenta a un vacío probatorio consistente en no poder demostrar cuál de los miembros del Grupo Negligente satisface el examen but for, porque "cada uno de dichos miembros puede señalar al otro como la posible causa" del daño ${ }^{70}$. Como bien señaló la corte, el vacío probatorio consiste en la imposibilidad de que:

"el demandante demuestre, en un balance de probabilidades, cuál de los individuos [los miembros del Grupo Negligente] causó de hecho el daño. Ésta es la imposibilidad probatoria de la que hablan Cook y los casos de mesotelioma de múltiples empleadores"7?.

La contribución de Clements al desarrollo de la Excepción del Individuo Indeterminado resulta notable principalmente por dos motivos. El primero es que, en lugar de restringir la aplicación de esta excepción a agentes o circunstancias específicas - como la Cámara de los Lores en Fairchild, al limitar su aplicación a casos de mesotelioma-, la jueza suprema McLachlin expresamente abrió la posibilidad de que esta excepción se aplique a cualquier otro caso que reúna ciertos requisitos. El segundo motivo consiste en haber demostrado que, a diferencia de la excepción McGhee, la Excepción del Individuo Indeterminado no está del todo reñida con las normas tradicionales de la causalidad fáctica ${ }^{72}$; sino que, por el contrario, es coherente con la lógica detrás del examen but for al exigir a la víctima acreditar que el daño provino de una conducta negligente.

Entender este segundo motivo resulta de vital importancia, por lo que conviene ahondar un poco más en él. Como ya se ha establecido, para que aplique la Excepción del Individuo Indeterminado, es indispensable contar, dentro de otros requisitos que se detallarán en la sección II.4.3.5 siguiente, con: a) Un Grupo Negligente; es decir, una pluralidad de individuos, cuyas conductas negligentes incrementaron el riesgo de que se ocasione un daño; $y, b$ ) un daño que es el resultado del riesgo que los miembros del Grupo Negligente incrementaron. Estos dos elementos se cumplen en el ejemplo de "una bala, dos cazadores", en los cuales existe: a) el Grupo Negligente, conformado por los dos cazadores, cada uno de los cuales aumentó negligentemente el riesgo de daño, al disparar sin las medidas de precaución razonables; $y, b$ ) el daño resultante del riesgo que cada cazador negligentemente incrementó, dado que la herida es causada por la bala disparada por uno de ellos.

En cada supuesto de hecho en que se verifiquen los dos elementos antes mencionados, debería existir convicción en el juzgador de que el daño fue causado por, al menos, una conducta negligente; lo cual constituye la esencia misma del examen but for. Lo antes afirmado representa una diferencia crucial con la excepción McGhee, en la que no hay certeza de que el daño haya sido causa de negligencia alguna, mientras que en la Excepción del Individuo Indeterminado se garantiza que la persona que causó el daño con su negligencia, quien necesariamente forma parte del Grupo Negligente, quede obligada a reparar el daño. Si bien es cierto que en muchos casos existirán también miembros del Grupo Negligente que, a pesar de no haber ocasionado el daño, se vean obligados a pagar la reparación —éste sería el caso del cazador que no disparó la "bala culpable"-, creo que este resultado se justifica por las razones que expongo en la sección II.4.3.7 siguiente.

70. Ibíd., párrafo. [46].

71. Ibíd., párrafo. [39].

72. Ibíd., párrafos [40], [46]. 
Es en virtud de lo anterior que se puede afirmar que, si bien bajo la Excepción del Individuo Indeterminado la causalidad fáctica no queda establecida respecto de un individuo en particular, sí se establece respecto del Grupo Negligente. Si nos preguntamos: ¿el daño se hubiese producido de no ser por los actos del Grupo Negligente? La respuesta debe ser "no", dado que, si sustraemos al Grupo Negligente de la figura, se hubiera evitado el daño; constituyendo los individuos de dicho grupo - vistos como un todo - una causa necesaria del daño.

En el ejemplo de "una bala, dos cazadores" nos debemos preguntar: ¿el transeúnte hubiese sido herido con una bala de no ser por la conducta de ambos cazadores? No. El daño se hubiese evitado si los cazadores se hubiesen abstenido de disparar sus respectivas balas; convirtiéndose a ambos cazadores, vistos como un conjunto, en causa necesaria del accidente y aprobándose así, al menos en forma lata, el examen but for.

\subsubsection{Características de la Excepción del In- dividuo Indeterminado.}

Los casos de Fairchild, Clements y los de "una bala, dos cazadores" tienen en común los siguientes cinco elementos, por lo que, si éstos se encontrasen presentes en algún caso de responsabilidad civil en el Derecho anglosajón, la Excepción del Individuo Indeterminado debería aplicarse. Primero, la existencia de un daño. Segundo, la existencia de múltiples personas -el Grupo Negligente-que, mediante una conducta negligente, incrementaron el riesgo de que se ocasione un daño. Tercero, que el daño sufrido por la víctima haya sido producto del mismo riesgo que se incrementó por la conducta de los demandados. Cuarto, la imposibilidad científica de determinar quién -entre dichos posibles bación del examen but for en sentido amplio; es decir, en el sentido de que el daño fue producto de la negligencia del Grupo Negligente visto en su conjunto.

Tomando a Fairchild como ejemplo, la viuda del Señor Fairchild demostró que el Señor Fairchild murió de mesotelioma. En segundo lugar, que el Señor Fairchild había sido expuesto negligentemente al asbesto por parte dos entidades diferentes: el Ayuntamiento de Leeds y Waddingtons $\mathrm{plc}^{73}$. En tercer lugar, la Cámara de los Lores quedó convencida de que el mesotelioma era el resultado de la exposición negligente al referido asbesto. En cuarto lugar, era científicamente imposible determinar cuál de las dos fuentes de exposición al asbesto - es decir cuál de las dos entidades-, o si ambas, habían causado el daño.

Aunque la Cámara de los Lores en Fairchild no estableció un porcentaje aproximado de exposición por cada entidad, supongamos que dicha exposición se distribuyó por igual entre ellas.

\begin{tabular}{|lc|}
\hline Fuente & Porcentaje \\
\hline $\begin{array}{l}\text { Entidad 1: } \\
\text { Ayundamiento de Leeds }\end{array}$ & $50 \%$ \\
\hline $\begin{array}{l}\text { Entidad 2: } \\
\text { Waddingtons plc }\end{array}$ & $50 \%$ \\
\hline Total & $\mathbf{1 0 0 \%}$ \\
\hline
\end{tabular}

En este caso, no se necesitaría un gráfico para ilustrar que la totalidad —el $100 \%$ - de las posibles causas fueron negligentes y que, globalmente y en sentido amplio, la prueba del examen but for se satisface fácilmente, cumpliéndose así el quinto requisito. 


\subsubsection{Diferencias con la causalidad probabi- lística.}

Hace algunos años, el profesor Alfredo Bullard ${ }^{74}$ planteó en nuestro medio una manera alternativa de ver la causalidad. En resumidas cuentas, el autor destacaba que las reglas tradicionales de la responsabilidad extracontractual, entre otros problemas, crean una lotería, en la cual no se castiga a la persona que actuó negligentemente, sino al que tuvo la "mala suerte" de causar un daño con su negligencia.

Para contrarrestar éste y otros problemas de la aproximación clásica a la causalidad, lo que se propone a través de la causa probabilística es crear mecanismos para que todas las personas que actúen negligentemente tengan una obligación de pago, sin que para ello sea relevante si su actuar causó un daño o no. ¿Cómo se calcula el monto a pagar? La propuesta consiste en multiplicar el potencial valor del daño por la probabilidad de que éste se verifique. De este modo, con el dinero que vaya pagando cada actor negligente, se podría ir creando una especie de "pozo", del cual saldrán posteriormente las indemnizaciones conforme los daños se vayan verificando.

Sin embargo, como el mismo autor parece reconocer, esta teoría de causalidad trae consigo al menos dos problemas. El primero, es que no es fácil cuantificar el potencial daño ni la probabilidad de que éste se materialice, por lo que podríamos tener a víctimas sub indemnizadas o sobre cobros a los actores negligentes. El segundo problema es que implementar la causa probabilística implica un cambio profundo en las reglas clásicas de la responsabilidad extracontractual, puesto que la causalidad probabilística pone en segundo plano al que es el eje central de la responsabilidad civil: el daño.
La Excepción del Individuo Indeterminado tiene la similitud con la causa probabilística en que en ambas aproximaciones a la causalidad existen personas que, a pesar de no haber causado un daño en los hechos, se ven obligadas a pagar una indemnización por su actuar negligente. No obstante, existen al menos tres diferencias. La primera, es que la Excepción del Individuo Indeterminado no busca convertirse en la regla general para establecer la causalidad, sino que busca constituirse en una figura absolutamente excepcional —debiéndose cumplir siempre los cinco requisitos detallados en la sección II.4.3.5. anterior- cuya única finalidad es la de superar un vacío probatorio particular.

La segunda radica en que la Excepción del Individuo Indeterminado no prescinde del daño como requisito para el pago de la reparación, sino que es recién cuando éste se verifica que la víctima tiene legitimidad para obrar. A falta de daño, ninguna de las personas del Grupo Negligente debe pagar ningún tipo de indemnización.

La tercera es que la Excepción del Individuo Indeterminado no se basa en probabilidades para determinar la indemnización, pues la "potencialidad" de que un daño ocurra es irrelevante. Por el contrario, convierte a todos los miembros del Grupo Negligente en responsables por el total del daño para asegurar una reparación integral de la víctima, sin "sobre" ni "sub" compensarla.

\subsubsection{Principales críticas y opinión.}

Luego de una amplia investigación realizada por Lord Bingham ${ }^{75}$ y Lord Rodger ${ }^{76}$ para el caso Fairchild, éstos concluyeron que las discusiones en torno a este vacío probatorio - es decir la imposibilidad de determinar al individuo causante dentro del Grupo Negligente- ni son

74. BULLARD GONZÁLEZ, Alfredo. "Causalidad Probabilística: El problema de los costos administrativos en el diseño de un sistema de responsabilidad civil extracontractual". En: Ius Et Veritas. Vol. 2, N 3, 1991.

75. Fairchild, párrafos [23]-[31] —Lord Bingham-.

76. Ibíd., párrafos [157]-[160] —Lord Rodger-. 
nuevas ni es exclusivas del Derecho anglosajón. Las raíces de este problema pueden remontarse incluso a los juristas romanos clásicos ${ }^{77}$.

La objeción más evidente y justa a la Excepción del Individuo Indeterminado es que existe el riesgo de que una persona quede obligada al pago de una indemnización a pesar de que su negligencia no causó, en los hechos, el daño ${ }^{78}$. Volviendo al ejemplo de "una bala, dos cazadores", si bien sabemos que uno de los cazadores disparó la bala que impactó en la víctima, también sabemos que el otro cazador no disparó la "bala culpable". Entonces, ¿por qué el Derecho haría responsable a quien no causó el daño? La crítica, por tanto, consiste en que, al hacer a ambos cazadores responsables, no sólo el Derecho estaría creando una "segunda víctima"79, sino que se está contraviniendo una de las metas de la responsabilidad civil: la "justicia correctiva", consistente básicamente en que quien causó el daño, y no otra persona, enmiende - o al menos apacigüe- el sufrimiento de la víctima mediante el pago de una indemnización a la víctima ${ }^{80}$.

La crítica es válida. Sin embargo, la alternativa para no crear una "segunda víctima" sería dejar a la víctima del daño sin reparación alguna; y considero que esta segunda opción sería mucho menos deseable. En efecto, cuando existe un conflicto entre dos derechos, debe preva- lecer el que sea más coherente con el ordenamiento jurídico ${ }^{81}$. En este caso, los derechos en contienda son: por un lado, el derecho del demandado a no ser considerado responsable de un daño que no ha causado; $y$, por el otro lado, el derecho de la víctima a obtener una reparación por un daño sufrido. Por las razones que expongo a continuación, pienso que el derecho de la víctima es el que debe prevalecer.

En primer lugar, debe tomarse en cuenta que la razón por la que la víctima no puede individualizar a la persona que causó el daño escapa a su control. No obstante, lo anterior sí se encontraba dentro del ámbito de control de los demandados, quienes decidieron ejercer el acto negligente.

En segundo lugar, en lo que a la víctima concierne, se han cumplido todos los presupuestos de la responsabilidad civil para obtener una indemnización: la existencia de un deber de cuidado, el incumplimiento de dicho deber mediante un actuar negligente, un daño $y$, en sentido amplio, un nexo causal que vincula la negligencia con el daño.

En tercer lugar, como bien se expuso en Clements ${ }^{82}$, brindarle una reparación a la víctima cumple con la mayoría de los objetivos subyacentes a la responsabilidad civil. En efecto ello

77. Ibíd. — Lord Rodger, Lord Bigham, coindiciendo en el párrafo [23]—.

78. Ibíd., párrafo. [33] —Lord Bingham-.

79. La primera víctima fue la que en efecto sufrió el daño. La segunda es el miembro del Grupo Negligente.

80. Clements, párrafo [8] —McLachlin CJ_. Vale decir que este objetivo busca otros resultados también, como el asegurar que el demandado pague únicamente por los daños causados y no se le imponga una reparación mayor —ni, lógicamente, menor-.

81. Así, por ejemplo, el Tribunal Constitucional del Perú ha señalado que los conflictos entre derechos fundamentales se resuelven mediante el criterio de "ponderación o proporcionalidad", debiéndose evitar pautas discrecionales como "sano juicio" o "criterio común" —En: EXP. N. 0 01470-2016-PHC/TC, párrafo [17] (Magistrado Espinosa-Saldaña Barrera) —. Si bien ninguno de los derechos materia de esta sección es un derecho fundamental per se, considero que debe aplicar una lógica similar, evitándose resolver el conflicto por simpatías — subjetivascon algún argumento e intentando elegir aquel derecho que sea más coherente con los principios, leyes y demás fuentes del Derecho.

82. Clements, párrafo [41] —McLachlin CJ-. 
cumple con las metas de: a) compensación, puesto que se indemniza a la víctima; b) prevención, dado que se evita que potenciales autores de daños queden inmunes a la responsabilidad civil sólo porque tuvieron la "fortuna" de que otras personas también cometieron su misma actividad negligente; $y$, hasta cierto punto, $c$ ) justicia correctiva, puesto que el demandado que sí causó en los hechos el daño es obligado a pagar la indemnización.

En cuarto lugar, considero que la creación de la "segunda víctima" no es una consecuencia exclusiva de otorgar una indemnización al demandante. Efectivamente, si se negase el resarcimiento sobre la base de que el demandante, por razones ajenas a su control ${ }^{83}$, fue científicamente incapaz de individualizar a un "responsable" dentro del Grupo Negligente, ello condenaría al demandante, quien ya fue víctima del daño, a soportar los efectos del daño sufrido, convirtiéndosele en doblemente víctima. La diferencia entre lo anterior y obligar al demandado que no causó el daño a pagar la indemnización es que esta denominada "segunda víctima" no es "inocente" puesto que, a diferencia del demandante, el demandado decidió actuar negligentemente ${ }^{84}$. En otras palabras: ¿quién debe soportar el costo de un daño? ¿la víctima, quien no actuó negligentemente y a pesar de ello sufrió el perjuicio? ¿o el demandado, quien, si bien tuvo la "fortuna" de no haber ocasionado el daño, tomó la decisión de actuar de manera negligente sabiendo - o debiendo saber - que su conducta podía derivar en un daño? Considero que el Derecho debe proteger al demandante.

En quinto lugar, al analizar estos casos, no pue- do evitar pensar en el argumento a fortiori. No cabe duda de que en todos estos supuestos, si hubiera existido un solo infractor, la víctima obtendría una indemnización ya que no habría dificultades para probar la relación de causalidad. Por ejemplo, reemplacemos el escenario de "una bala, dos cazadores" por uno de "una bala, un cazador", en el cual solo existe el Cazador 1 y su disparo negligente es el que falla al objetivo, hiriéndose al transeúnte. En este caso, no existiría duda alguna sobre la relación causal entre el daño y el autor; y la víctima obtendría reparación. Por tanto, si una sola conducta negligente hubiera bastado para que el demandante obtuviera una indemnización, a fortiori, dos conductas negligentes deberían ser más que suficientes para indemnizar a la víctima. Como correctamente explicó Lord Bingham en Fairchild, sostener lo contrario sería adoptar una interpretación estrecha de las reglas de causalidad, según la cual:

"si hubiera habido un solo autor del daño, $C$ [el demandante] hubiese tenido derecho a obtener una compensación, pero como el deber de cuidado que se le debía fue incumplido por dos actores negligentes, y no por uno sólo, entonces $C$ no puede obtener compensación frente ninguno de ellos, debido a su incapacidad de acreditar lo que científicamente no se puede probar ${ }^{1 / 85}$.

Es por las razones antes expuestas que considero que - aunque se debe proceder con cautela, según explico en las secciones siguientesdebe preferirse una reparación al demandante a pesar de la creación de la "segunda víctima". No obstante, ello no significa que la Excepción

83. Ibíd., párrafo [46].

84. Como se advierte en Clements, calificar al demandado como una "segunda víctima, pero no inocente" puede objetarse en el sentido de que uno sólo es "culpable" con respecto a los daños que efectivamente causa, por lo que la conducta de quien no causó un daño resulta irrelevante para efectos de la responsabilidad civil. Si bien esta objeción sería válida, considero que no se puede perder de vista que, a diferencia del demandante, el demandado estaba en mejor posición de controlar las consecuencias de sus actos; por lo que sí resulta relevante que el demandado haya decidido ejecutar el acto negligente a sabiendas de que ello podía derivar en una indemnización. De alguna manera, el demandado internalizó las posibles consecuencias de su actuar negligente; lo que, perdonándose la expresión, no lo hace tan "inocente" como al demandante.

85. Fairchild, párrafo [9] —Lord Bingham-. 
del Individuo Indeterminado sea una institución consolidada y libre de críticas.

Por ejemplo, un cuestionamiento que se puede realizar es cómo aplicaría la Excepción del Individuo Indeterminado en supuestos donde uno de los posibles autores aumentó el riesgo de daño más que el resto. Tomemos el ejemplo de "una bala, dos cazadores", pero imaginemos un escenario en el que, mientras que el Cazador 1 disparó una sola bala, el Cazador 2 disparó dos balas consecutivas. Si bien sólo una de las balas impactó al transeúnte, el Cazador 1 disparó un tercio de las balas y el Cazador 2 dos tercios, teniendo más chances de haber causado el daño. En este escenario: ¿se debería considerar que, en el balance de las probabilidades, únicamente al Cazador 2 como el responsable del daño? ¿se debería responsabilizar a ambas personas, pero en proporción a su incremento en el riesgo, obligando al Cazador 1 a pagar el 33.33\% de los daños y al Cazador 2 el $66.66 \%$ de la indemnización? ¿o se debería considerar a ambos solidariamente responsables?

A la fecha, en postura que comparto, los tribunales anglosajones han adoptado esta última aproximación y se han mostrado reacios a basar sus análisis causales en simples probabilida$\operatorname{des}^{86}$. Así por ejemplo, en uno de los casos que se acumularon en Fairchild, la Cámara de los Lores condenó a todos los demandados al pago de la indemnización, y se rehusó a considerar a uno de ellos - el empleador Associated Portland Cement Manufacturers- como el único causante del mesotelioma del Señor Matthew, a pesar de que la gran mayoría de su exposición al asbesto provino del referido demandado.
En efecto, considero que esta aproximación es la adecuada puesto que, en estos escenarios, no puede descartarse la posibilidad de que alguno de los otros miembros del Grupo Negligente —que también incrementaron "materialmente" el riesgo - haya sido el autor del daño; y considerar al que creó más riesgo como el "único autor", sería negar dicha posibilidad. Empero, reconozco que, en algunos ordenamientos jurídicos -incluyendo el anglosajón- ${ }^{87}$, podría abogarse para que, en lugar de una solidaridad, cada demandado únicamente pague la indemnización proporcional al riesgo creado.

\section{LA EXCEPCIÓN DEL INDIVIDUO INDETER- MINADO EN LAS LEGISLACIONES COM- PARADAS}

Como se indicó en la sección II.4.3.7 precedente, el problema que la Excepción del Individuo Indeterminado intenta atacar -el autor no identificado dentro del Grupo Negligente- no es exclusivo del Derecho anglosajón. Al respecto, cabe mencionar que si bien existirían algunas jurisdicciones que negarían compensación a la víctima en estas situaciones ${ }^{88}$, existen muchas otras que han positivizado la Excepción del Individuo Indeterminado. A continuación, se presentan algunos ejemplos.

\section{Alemania.}

En el artículo 830.1 del Bürgerliches Gesetzbuch-BGB se establece que:

"[s]i varias personas han causado un daño mediante un acto ilegal cometido en común,

86. LALENG, Per. Op. Cit. Cabe precisar, además que incluso el examen but for no se basa exclusivamente en las probabilidades presentadas por la ciencia, sino que se requiere de una valoración de las pruebas por parte de cada juez para determinar qué causa fue la que, con certeza, causó el daño.

87. Pero excluyendo al Derecho peruano, puesto que — como se explicará en la sección IV siguiente- esta excepción, de aplicarse en el Perú, necesariamente debería calzar bajo los alcances del artículo 1983 del Código Civil peruano, el cual ordena la solidaridad entre los demandados.

88. Ello de acuerdo a lo mencionado por Lord Bingham en Fairchild quien, juzgando por la regulación de ciertas jurisdicciones, considera que en países como Italia, Sudáfrica y Suiza se negaría indemnización, aunque no presenta mayor análisis ni soporte al respecto —En: Fairchild, párrafos [23]-[32] (Lord Bingham)—. 
cada una es responsable por el daño. Esta misma regla aplica si no se puede determinar quién, dentro de los diversos participantes, causó el daño" -énfasis agregado-.

El segundo párrafo ha sido aplicado en al Alemania ${ }^{89}$ en un caso en el cual el daño fue ocasionado por una de las varias personas que se encontraban lanzando piedras y fue imposible determinar quién había lanzado la "piedra culpable" que hirió a la víctima. Otro caso en el que se aplicó esta disposición fue el de un transeúnte que sufrió un daño al pasar por una construcción en donde operaban diversas compañías y era imposible saber cuál de las compañías había ocasionado el daño al demandante.

\section{Los Países Bajos.}

De similar manera, los legisladores holandeses parecen haber entendido perfectamente el problema del "autor no identificado dentro del Grupo Negligente" toda vez que, de conformidad con el artículo 6.99 del Código Civil holandés,

\begin{abstract}
"[c]uando el daño pueda haber resultado de dos o más eventos, cuyos creadores son personas distintas, y cuando se haya demostrado que el daño se ocasionó de al menos uno de estos eventos, la obligación de reparar el daño recae en cada una de estas personas, a menos de que cualquiera de ellas pruebe que el daño no es el resultado del evento que ésta creó".
\end{abstract}

\section{Argentina.}

En Latinoamérica, en el Código Civil y Comercial argentino también se ha insertado una disposición en este sentido. En el artículo 1761 de dicho cuerpo normativo, se ha establecido que: "[s]i el daño proviene de un miembro no identificado de un grupo determinado responden solidariamente todos sus integrantes, excepto aquel que demuestre que no ha contribuido a su producción".

Esta norma merece un comentario especial puesto que, si bien se trata de una disposición similar a alemana y holandesa, se diferencia de la Excepción del Individuo Indeterminado en dos extremos.

El primero es que, de una lectura literal de este artículo, pareciera que en éste no se exige al demandante probar que todos los miembros del grupo demandado incrementaron el riesgo mediante el ejercicio de la actividad negligente. Por el contrario, sólo se exige al demandante señalar o delimitar un grupo y corresponderá a cada uno de los miembros acreditar que él no formó parte de la actividad, constituyendo ésta una norma más favorable para la víctima que las anteriores.

El segundo es que, según se señala en la doctrina argentina, el factor de atribución aplicable a esta disposición es el objetivo, "por lo cual será irrelevante la subjetividad de la conducta de los integrantes del grupo a los fines de determinar su responsabilidad"90; lo cual contrasta con la Excepción del Individuo Indeterminado, en el cual la prueba de negligencia es necesaria.

Sin perjuicio de lo anterior, es claro que los legisladores argentinos tuvieron el problema del "autor no identificado dentro del Grupo Negligente" en mente al momento de la creación de esta norma.

IV. ¿PODRÍA APLICARSE LA EXCEPCIÓN DEL INDIVIDUO INDETERMINADO EN EL DERECHO PERUANO?

A diferencia de las legislaciones a las que hice referencia en la sección III anterior, el Código Civil peruano no contiene alguna regulación expresa para atacar el problema del "agente desconocido dentro del Grupo Negligente". Desde

89. Idem.

90. SAENZ, Luis R. J. “Comentarios al artículo 1761 del Código Civil y Comercial de la Nación”. En: KANDUS, Cecilia (Coordinadora). Código Civil y Comercial de la Nación Comentado. Buenos Aires: 2016, Editorial Ministerio de Justicia y Derechos Humanos de la Nación, p.489 
luego que ello no necesariamente significa que la Excepción del Individuo Indeterminado no se pueda utilizar en el Perú.

En tal sentido, luego de realizar un repaso muy general sobre las principales normas de causalidad en el Código Civil peruano, propondré cómo, en mi opinión, la Excepción del Individuo Indeterminado podría ser aplicada en el Perú.

\section{Preámbulo: Principales características del nexo causal bajo la ley peruana.}

En resumidas cuentas, para el Código Civil peruano debe existir una "relación de causalidad adecuada entre el hecho y el daño produci$\mathrm{do}^{\prime \prime 91}$. Si bien no existe una definición a nivel legislativo del término "causalidad adecuada", Fernando de Trazegnies ofrece la siguiente definición — la cual es generalmente aceptada en nuestro medio-: ésta es "la causa, dentro de la universalidad de causas que encarna cada situación, que conduce usualmente al resultado dañino".92

Este concepto de "usual" o "normal" no debe ser evaluado a la luz de las circunstancias concretas del accidente en particular; sino que, por el contrario, debe realizarse una evaluación objetiva - esto es, abstracta- sobre qué, en términos generales, debe ser considerado como un resultado "usual" de una determinada acción. ${ }^{93}$ Adicionalmente, en el análisis causal es necesario excluir aquellos resultados que, por su lejanía con el acto u omisión generador del daño, no pueden ser considerados como resultados usuales o normales; lo que quiere decir que se excluyen los denominados "daños remotos". En tal sentido, como regla general, la reparación se debe a quien sufre un daño dentro de la esfera de riesgo que normalmente conlleva la actividad del demandado.

Por otra parte, el Código Civil peruano sí prevé la posibilidad de que la causa adecuada esté conformada por diversos hechos o factores; incluyendo varios autores, en cuyo caso todos ellos responden solidariamente frente al damnificado. ${ }^{94}$ En este supuesto, el juez fija la proporción que, en la relación interna entre los responsables, le corresponde a cada uno; y, si no fuera posible determinarla, la repartición se hace en partes iguales. ${ }^{95}$

\section{La Excepción del Individuo Indetermina- do no está positivizada.}

Como se desprende de la sección IV.1 anterior, la normativa acerca de los múltiples autores en el artículo 1983 del Código Civil peruano parte de la premisa de que las personas responsables por el daño han sido identificadas y se ha determinado que todas ellas fueron la causa adecuada del daño.

Si bien la referida norma ofrece una solución cuando no se puede identificar el grado de participación de los responsables identificados, la cual consiste en la distribución de la indemnización en partes iguales en la relación interna entre los coautores, cubriendo así el vacío probatorio del "daño indivisible" —en el que no se puede probar el grado de participación de cada autor en el daño- el citado artículo no contiene una solución para el vacío probatorio de no poder identificar exactamente quién, o quiénes, dentro del Grupo Negligente, causaron efectivamente el daño.

91. Código Civil peruano, Artículo 1985 —énfasis agregado-.

92. DE TRAZEGNIES GRANDA, Fernando. Op. Cit., p. 313 —énfasis agregado-.

93. Ibíd, p. 313 —énfasis agregado-.

94. Código Civil peruano, Artículo 1983.

95. Ibíd. 
En tal sentido, podría concluirse que, si el demandante no lograse identificar judicialmente a dicha persona - o dichas personas-, entonces la demanda deberá ser declarada infundada. Sin embargo, creo que esta conclusión sería incorrecta, según explico a continuación.

\section{Posible aplicación de la Excepción del In- dividuo Indeterminado en el Perú.}

La falta de regulación antes relatada podría calificar como un vacío en el Código Civil puesto que no se ha legislado una situación que, conforme a lo desarrollado en la sección II.4.3.7 anterior, merece tutela. Bajo este argumento, resulta de aplicación lo dispuesto en el artículo 139 de la Constitución Política del Perú y del artículo VIII del Título Preliminar del Código Civil peruano ${ }^{96}$ y el juez deberá de administrar justicia en favor del damnificado sustentándose en los principios del Derecho Peruano, como los principios de pronta e integral reparación de la víctima, prevención del daño y justicia correctiva, sobre los cuales se ha inspirado, en mayor o menor medida, el Código Civil peruano ${ }^{97}$.

No obstante, pienso que existe una manera de armonizar las actuales reglas positivas de responsabilidad extracontractual con la Excepción del Individuo Indeterminado, con lo que los jueces podrían evitar recurrir a la aplicación del referido artículo VIII del Título Preliminar.

\subsection{Aquellos casos que admiten la posibili- dad de múltiples factores.}

Ligeramente menos complicados de resolver son los casos en los que el daño pudo haber sido causado o bien por un miembro del Gru- po Negligente o bien por una combinación de cualquier conjunto de miembros dentro del grupo, incluyendo la posibilidad de que haya sido causado por todos ellos - a estos supuestos los denominaremos "múltiples posibles factores" - . Tal sería la situación de, por ejemplo, el caso planteado en la introducción de este trabajo, en el que cada poblador pudo haber sido envenenado por desechos negligentemente vertidos por CMA, por MS o por un cóctel de desechos. Éste también sería el caso de las personas que contraen mesotelioma ya sea producto de una sola fibra del asbesto a la que la víctima fue expuesta por uno de los empleadores dentro de un Grupo Negligente o de una acumulación de fibras del asbesto - cuya exposición es atribuible a más de uno de los empleadores pertenecientes a un Grupo Negligente-

Para estos casos de múltiples posibles factores, considero que - bajo las normas actuales del proceso civil en el Perú- el demandante no tiene la carga de probar exactamente qué factor le causó el daño. En efecto, el estándar de prueba requerido por la legislación peruana no exige que, en el ejemplo planteado en la introducción, cada habitante del poblado demuestre puntualmente cuál de las dos compañías, o si ambas en conjunto, vertió o vertieron en el río la partícula exacta de arsénico o mercurio que lo envenenó.

Pienso, por el contrario, que para que la causalidad quede establecida en los casos de múltiples posibles factores, bastará que la víctima acredite los siguientes elementos: a) haber sufrido un daño; b) que todos los demandados incrementaron el riesgo del daño al cometer la conducta

96. Artículo 139 de la Constitución Política del Perú: "Son principios y derechos de la función jurisdiccional: (...) 8. El principio de no dejar de administrar justicia por vacío o deficiencia de la ley. En tal caso, deben aplicarse los principios generales del derecho y el derecho consuetudinario".

Artículo VIII del Título Preliminar del Código Civil- "Los jueces no pueden dejar de administrar justicia por defecto o deficiencia de la ley. En tales casos, deben aplicar los principios generales del derecho y, preferentemente, los que inspiran el Derecho peruano". 
negligente que se les imputa; ${ }^{98} \mathrm{y}, \mathrm{c}$ ) que si bien es científicamente imposible determinar exactamente quién o quiénes causaron en los hechos el daño, se ha probado que el perjuicio provino del actuar de uno o más de los demandados; o al menos que el daño se encuentra dentro de la esfera del riesgo que se incrementó por la actividad realizada por todos ellos. Acreditado ello, el juzgador deberá evaluar si es que el elemento a) es una consecuencia usual de la conducta descrita en el elemento b). De ser afirmativa esta última respuesta, habrá causa adecuada entre el daño y la conducta de todos los demandados.

En el ejemplo planteado en la introducción, bastará entonces con que cada habitante pruebe que ha sido envenado con mercurio y/o arsénico, que tanto CMA como MS vertieron dichos elementos químicos en el río - con lo que se acredita que el daño se encuentra dentro de la esfera de riesgo creada por dichas sociedades-y que, si bien el envenenamiento pudo haber sido producido sólo por la conducta de una de las dos compañías, también es posible que dicho daño sea el resultado del consumo del cóctel de desechos tóxicos de ambas sociedades. ${ }^{99}$ Demostrado lo anterior, el juzgador deberá preguntarse: ¿el envenenamiento de los habitantes de un poblado instalado río abajo es un resultado normal de que dos compañías hayan vertido residuos tóxicos en el río? No cabe duda de que la respuesta es afirmativa y que, por las normas de la causalidad adecuada y de la pluralidad de responsables, ambas sociedades deberán responder solidariamente ${ }^{100}$.

Esta misma línea de pensamiento es compartida por Fernando de Trazegnies ${ }^{101}$ cuando brinda el ejemplo de una vivienda que resulta dañada por el humo de varias fábricas y no es posible determinar si fue el humo de una, de algunas o de todas, lo que causó el daño; ante lo cual el autor concluye que todas las fábricas deben responder solidariamente frente a la víctima.

Con ello, se tiene que la causalidad adecuada regulada en la legislación peruana resulta perfectamente compatible con la Excepción del Individuo Indeterminado cuando nos encontramos ante casos que admiten múltiples posibles factores.

\subsection{Casos que únicamente permiten la exis- tencia de un solo factor.}

Un nivel mayor de complejidad se advierte en los daños que no pueden ser causados por múltiples personas y que solamente se explican por uno de los miembros del Grupo Negligente - a estos supuestos, los podemos llamar casos de "factor único"- Tal es el ejemplo de "una bala, dos cazadores", en el que el transeúnte no

98. Como se explicará con más detalle en la sección siguiente, y de conformidad con el artículo 1969 del Código Civil peruano, el demandante sólo tendrá que acreditar que el demandado cometió la conducta que el primero de ellos alega; correspondiéndole al demandado el descargo por negligencia. Sin embargo, para que se declare fundada la demanda, el juez deberá tener la certeza de que el actuar de los demandados fue, cuando menos, negligente.

Por otro lado, si la conducta consiste en una actividad — o el uso de un bien — riesgosa o peligrosa, se prescindirá del análisis de la negligencia en el actuar de los individuos del Grupo Negligente — siendo este tema materia de desarrollo también en la sección IV.3.2 siguiente-.

99. Por el contrario, si se determinase que el daño únicamente pudo haber provenido de uno de los posibles autores -en este caso, solamente de los desechos de una compañía, excluyéndose la posibilidad del cóctel de residuos-, este supuesto calzaría dentro del escenario del "factor único", tratado en la sección IV.3.2 siguiente.

100. Naturalmente, este análisis se centra únicamente en la responsabilidad civil extracontractual que pueda aplicar y excluye toda responsabilidad penal, administrativa o cualquier otra consecuencia que por ley corresponda.

101. DE TRAZEGNIES GRANDA, Fernando. Op. Cit. p. 581. 
puede alegar que su daño fue físicamente causado por los dos disparos puesto que es claro que solamente una bala lo hirió.

Cabe precisar que, si bien el caso de "una bala, dos cazadores" puede no ser el ejemplo más característico de este problema bajo la legislación peruana puesto que la caza, al implicar el uso de un arma de fuego, es considerada una actividad riesgosa a la luz del artículo 1970 del Código Ci$\mathrm{vil}^{102}$, otros ejemplos muy similares pueden proponerse cambiando sólo algunos detalles. Tenemos así el caso de los dos golfistas que practican diversos tiros en un espacio público sin tomar las medidas de precaución razonables, para luego descubrir que una de las bolas lanzadas había golpeado, y roto, la ventana de un automóvil que se encontraba estacionado dentro del radio de práctica. Al igual que en el ejemplo de los cazadores, tenemos a un Grupo Negligente, conformado por ambos golfistas, y a un daño causado por un factor único puesto que solamente una bola dañó al auto. Así puede haber muchos otros ejemplos y, a raíz del texto del Código Civil, podrá haber discusiones sobre si el bien o la actividad es peligrosa; lo cual deberá analizarse caso por caso.

Sin perjuicio de la salvedad antes mencionada, considero que la Excepción del Individuo Indeterminado es perfectamente aplicable a todos los casos que involucren un bien o actividad riesgosa o peligrosa. En efecto, si bien uno de los requisitos para que aplique dicha excepción bajo el Derecho anglosajón es que la actividad que incrementa el riesgo sea negligente, ése siempre ha sido un requisito previsto por la legislación peruana para la responsabilidad civil; y en los supuestos de hecho que se encuentren dentro de los alcances del artículo 1970 del Código Civil peruano, solo se tendrá que prescindir, como lo hace la norma, del análisis de culpa o dolo en la actividad que causa el daño. Dicho de otro modo, para la aplicación de la Excepción del Individuo Indeterminado en los casos que no impliquen un bien o actividad riesgosa o peligrosa, se deberá analizar eventualmente - como en todo estudio de responsabilidad civil en el Perú- si la conducta del determinado grupo fue negligente o no; $y$, para los casos que sí impliquen un bien o actividad riesgosa o peligrosa, el análisis de negligencia del grupo será irrelevante y se pasará a evaluar si el daño es consecuencia del riesgo creado por los individuos del grupo.

Ahora bien, dejando de lado el análisis del factor de atribución, el problema que encuentro con aplicar la Excepción del Individuo Indeterminado a situaciones de factor único es que hacer a ambos cazadores responsables cuando sólo una de las balas hirió al transeúnte parece un tanto forzado. Sin embargo, esta percepción se debe a que la pregunta subyacente a ese razonamiento puede no ser la correcta. Me explico: si se intenta encontrar la causalidad mediante la pregunta "¿quién disparó la bala que hirió al transeúnte?" o "¿quién lanzó el tiro responsable por romper el vidrio del carro?" nunca se hallará una respuesta debido a las limitaciones científicas; $y$, si de dicha respuesta depende la decisión de otorgar o no compensación a la víctima, esta última -injustamente- quedaría sin resarcimiento alguno. No obstante, la teoría de la causa adecuada nos permite tomar una ruta alternativa gracias a su inherente flexibilidad.

Dentro de las principales críticas que ha recibido la causalidad adecuada se encuentra su falta de precisión, puesto que determinar qué es un resultado "normal" o "usual" de una acción es una tarea compleja que depende, en gran medida, del criterio del juzgador ${ }^{103}$. No debe perderse de vista, empero, que esta falta de precisión no es producto de un descuido del legislador, ni de una pobre técnica legislativa. La causalidad

102. Artículo 1970 del Código Civil peruano.- "Aquel que mediante un bien riesgoso o peligroso, o por el ejercicio de una actividad riesgosa o peligrosa, causa un daño a otro, está obligado a repararlo".

103. Lo mismo puede decirse de otros requisitos de la responsabilidad civil, como la determinación de la culpa, en la que recae en el juzgador determinar qué es una conducta razonable. 
adecuada fue así diseñada y es adrede que la causalidad en el Código Civil peruano no es una "receta mágica" ni una "operación matemática"; sino que es una mera orientación para permitir a los juzgadores crear una "jurisprudencia rica, rigurosa y equitativa"104.

Considero, por tanto, que la causalidad adecuada constituye una herramienta lo suficientemente flexible y equitativa para resolver estos casos de factor único al permitirnos retroceder un paso en la cadena de causalidad. En vez de preguntarnos: "¿Quién disparó la bala que hirió al transeúnte?", cuya respuesta constituiría la causa fáctica inmediatamente anterior al accidente, podríamos preguntarnos: "¿Se encuentra dentro de la esfera del riesgo creado por los cazadores que una de las balas disparadas hiera a un transeúnte?" $\mathrm{O}$, dicho de otro modo, "¿si dos cazadores fallan en su objetivo, es una consecuencia normal que al menos una de las balas impacte en algún otro objeto o persona cercana al objetivo?". En cualquiera de las variantes de esta pregunta, en mi opinión la respuesta es afirmativa, concluyéndose que el daño del transeúnte es adecuadamente explicado con el actuar de ambos cazadores.

Ésta también parece haber sido la postura de la Corte de Casación francesa en Litzinger, en donde la referida corte declaró que, a pesar de que solamente una de las balas había impactado en el demandante, "la verdadera causa del accidente fue la acción concertada de los siete cazadores que dispararon sus armas". En este mismo sentido se ha pronunciado además, la doctrina internacional, según la cual se debe "situar así la causa del daño, no ya en el hecho material directamente dañoso (el disparo), susceptible de identificación in- cierta, sino en la anterior actitud, común a todos los interesados $(. . .)^{\prime \prime 05}$.

Esta misma línea de pensamiento, por ende, se debe aplicar en todos los casos que presenten el problema del "autor no identificado dentro del Grupo Negligente", en los cuales se deberá vincular el daño no con la causa fáctica inmediatamente anterior al perjuicio, la cual es imposible de descubrir, sino con la actividad que incrementó materialmente el riesgo y que fue realizada por todos los miembros del Grupo Negligente.

Ante esta manera alternativa de plantear la causa adecuada, alguien podrá objetar que existe el riesgo de retroceder infinitamente en la cadena de eventos que precedieron al daño hasta encontrar un responsable. Sin embargo, creo que esta objeción carece de validez cuando se toma en cuenta que dicho retroceso siempre debe encontrarse dentro de los límites de lo usual u ordinario y, en contraste, de lo remoto. En mi opinión, la herida de una bala no es un resultado remoto de que dos cazadores disparen sus armas dentro del rango de distancia donde se encontraba el transeúnte.

Considerando lo anterior, pienso que, en los escenarios de factor único, bastará con que la víctima acredite los mismos presupuestos que los señalados para los casos de múltiples posibles factores -explicados en la sección IV.3.1 anterior-; esto es: a) haber sufrido un daño; b) que todos los demandados incrementaron el riesgo del daño al cometer la conducta negligente que se les imputa $\left.{ }^{106} ; y, c\right)$ que si bien resulta científicamente imposible determinar exactamente quién causó en los hechos el daño, se ha probado que el perjuicio provino del actuar de uno de los demandados; o al

104. DE TRAZEGNIES GRANDA, Fernando. Op. Cit. p. 417-418.

105. CARBONNIER, Jean. Derecho Civil. Tomo II. Vol. III. Barcelona: Editorial Bosch, 1971, p. 78 — citado por BARRÍA, Rodrigo. "El daño causado por el miembro indeterminado de un grupo y su posible recepción en el derecho civil chileno". En: Revista de Derecho Escuela de Postgrado. N 01, Chile, p. 162-.

106. Como ya se adelantó, si el daño fue cometido mediante un bien o actividad riesgosa o peligrosa, se prescindirá del análisis de la negligencia en el actuar de los individuos del Grupo Negligente. 
menos que el daño se encuentra dentro de la esfera del riesgo incrementado por la actividad realizada por todos ellos ${ }^{107}$. Al igual que con los casos de múltiples posibles factores, demostrados los elementos anteriores, el juzgador únicamente deberá evaluar si el requisito a) es una consecuencia usual de la conducta descrita en el ítem b). De ser éste el supuesto, existirá una causa adecuada entre el daño y la conducta de los demandados.

Con ello, la causalidad adecuada regulada en el Perú también resulta compatible con la Excepción del Individuo Indeterminado aun en casos de factor único.

\section{La Excepción del Individuo Indetermina- do debe aplicarse con cautela.}

Si bien la causa adecuada resulta compatible con la teoría del incremento material del riesgo, en su Excepción del Individuo Indeterminado, ello no quiere decir que esta aproximación a la causa debe ser usada de una manera descuidada.

En efecto, si bien este vacío probatorio en particular puede cubrirse al retroceder un paso en la cadena de causalidad fáctica, la Excepción del Individuo Indeterminado no exonera al demandante de acreditar todos los presupuestos que se detallaron en las secciones IV.3.1 y IV.3.2 anteriores, incluyendo la prueba de que todos los demandados, en efecto, cometieron la actividad que incrementó el riesgo del daño. Un ejemplo puede ayudar a ilustrar las consecuencias de una aplicación no rigurosa de esta excepción.
Imaginemos que, como parte de una celebración del año nuevo, algunas de las familias que habitan en distintas casas que forman parte de un condominio deciden detonar productos pirotécnicos desde los patios o azoteas de sus respectivos hogares. Como consecuencia de ello, uno de los proyectiles termina impactando en un inmueble cercano al condominio, causándole daños. Ahora supongamos que, debido a las condiciones particulares en que se produjo el daño, la víctima puede acreditar que efectivamente el pirotécnico que le causó el perjuicio fue lanzado desde una de las casas del condominio en cuestión.

Si bien un análisis poco cuidadoso de este ejemplo podría llevar a concluir que, demostrado lo anterior -es decir que el daño provino de una de las casas del condominio-, se debería obligar a todos sus residentes al pago de la indemnización, ello sería un error. En efecto, para que aplique la Excepción del Individuo Indeterminado no basta con delimitar que el daño provino de uno de los miembros de un grupo. Se requiere, adicionalmente, probar quiénes son los miembros del grupo que incrementaron el riesgo del daño. En el caso antes planteado, no basta con acreditar que el proyectil provino del condominio, sino que el demandante debe también identificar quiénes son los residentes del referido condominio que estuvieron detonando los productos pirotécnicos cuando el daño ocurrión ${ }^{108}$. Tal sería el supuesto si es que el demandante logra acreditar en el proceso mediante cualquier medio probatorio permitido, como videos, testimonios, pericias practicadas en los hogares en búsqueda de rastros de

107. De manera similar, la doctrina argentina, al comentar el artículo 1761 del Código Civil y Comercial argentino ya citado, ha indicado que "el damnificado deberá probar que sufrió un daño, que ese daño le resulta atribuible a un sujeto no identificado dentro de un grupo determinado y que existe relación causal entre el hecho y el daño atribuido a ese miembro anónimo. Todos ellos responderán solidariamente" —En: CHRISTELLO, Martín. "Algunas notas sobre la responsabilidad colectiva y anónima en el nuevo Código Civil". En: Revista Reformas Legislativas. Debates Doctrinarios. Código Civil y Comercial. Año 1, № 01, Argentina, p. 26-. Sin embargo, la gran diferencia entre el caso peruano y el argentino es que en este último sí existe una norma expresa prevista para esta situación, lo que alivia en gran medida la probanza del nexo causal, el cual se puede establecer respecto del "miembro anónimo".

108. Sostener lo contrario implicaría que el demandante puede elegir, a su libre discreción, cuál es el grupo que debe pagar la indemnización, cuando — justamente por el carácter excepcional de esta figura- dicho grupo únicamente debe estar conformado por aquellos individuos que incrementaron el riesgo de la ocurrencia del daño. 
pólvora y otros fragmentos, etcétera - que al menos fueron los residentes de las casas 3, 5 y 8 quienes estuvieron encendiendo pirotécnicos ese día; en cuyo caso el "Grupo Negligente" estaría compuesto únicamente por dichos residentes y solamente respecto de ellos se podría establecer el nexo causal.

En efecto, es necesario recordar que no sólo esta excepción, sino que también las normas del proceso civil $^{109}$, imponen al demandante la carga de la prueba respecto a los hechos que alega; siendo la única excepción —en materia de responsabilidad extracontractual — la prueba de negligencia, cuyo descargo corresponde al demandado ${ }^{110}$. No obstante, esta inversión de la carga de la prueba no libera la demandante de acreditar que el demandado cometió el acto que se alega.

En términos más técnicos, y a diferencia del Código Civil y Comercial argentino, en el ordenamiento jurídico peruano la inversión de la carga de la prueba en materia extracontractual alcanza solamente al "factor de atribución", que implica una calificación jurídica: determinar si un acto fue negligente o no, y no a la causalidad, la misma que parte de un análisis fáctico: determinar si los hechos alegados efectivamente sucedieron o no. Lo anterior no sólo es avalado por la doctrina ${ }^{111}$ sino que resulta evidente puesto que sostener lo contrario - es decir que la inversión de la carga de la prueba se extiende a los hechos alegados- carecería de sustento normativo y traería al menos dos inconvenientes. El primero es que trasladaría al demandado la imposible labor de probar un hecho negati$v^{112}$. El segundo es que esta inversión de la carga de la prueba implicaría, en la práctica, una flexibilización tal en la carga del demandante de acreditar la legitimidad para obrar en el proceso, que ampliaría casi indeterminadamente el radio de posibles demandados. Y si bien el derecho de acción permite a cualquier persona iniciar un proceso en contra de cualquier otra, estas cargas en cabeza del demandante son uno de los principales factores que desincentivan demandas carentes de sustento probatorio.

Por ende, en ningún caso debería relevarse al demandante de acreditar que cada uno de los demandados en efecto incrementó el riesgo del daño mediante su conducta puesto que la Excepción del Individuo Indeterminado no busca que "justos paguen por pecadores". Muy por el contrario, para que esta excepción proceda, todos los miembros del grupo demandado deben ser, justamente, "pecadores" de cometer el mismo acto que derivó en el daño; dejándose a salvo el derecho de cada uno de esos "pecadores" de llenar el vacío probatorio y demostrar que, si bien su conducta incrementó el riesgo, no causó el daño.

\section{CONCLUSIONES}

Para el Derecho anglosajón, el incremento material del riesgo es una alternativa al examen

109. Artículo 196 del Código Procesal Civil peruano.- "Salvo disposición legal diferente, la carga de probar corresponde a quien afirma hechos que configuran su pretensión, o a quien contradice alegando nuevos hechos".

110. Puesto que, contrario al texto del artículo 1969 del Código Civil peruano, existen argumentos para sostener que la inversión de la carga de la prueba no alcanza al "dolo", dado que éste nunca se presume —DE TRAZEGNIES GRANDA, Fernando. Op. Cit. p. 165-.

111. DE TRAZEGNIES GRANDA, Fernando. Op. Cit. p. 165.

112. Si bien es la víctima quien tiene que demostrar en el proceso que todos los demandados incrementaron el riesgo con su actuar, cada uno de estos últimos podrá presentar pruebas que: a) contradigan las presentadas por el demandante; acreditando así que se le(s) debe excluir del Grupo Negligente; y/o b), demuestren quién ha sido el verdadero autor del daño, aunque esto último puede no ser realista justamente a raíz de la "imposibilidad" de determinar quién fue la persona que en los hechos causó el perjuicio. Sin embargo, lo anterior no quiere decir que la carga de la prueba haya sido invertida. Sólo quiere decir que, naturalmente, los demandados pueden hacer uso de su derecho a la defensa y demás facultades derivadas del derecho al debido proceso. 
but for que permite al demandante establecer una causalidad fáctica entre el daño y la conducta negligente que incrementó el riesgo de que éste ocurra, en aquellos supuestos en que existe un vacío probatorio que impide a la víctima acreditar que, en el balance de probabilidades, el demandado causó el daño.

El incremento material del riesgo, a su vez, se ha aplicado en dos tipos de casos distintos, siendo la Excepción del Individuo Indeterminado aquella que resulta la más coherente con los principios que rigen la responsabilidad extracontractual en el common law. Esta excepción, además, constituye una forma eficaz y deseable de evitar que potenciales autores de daños aprovechen un vacío probatorio en su favor para obtener inmunidad frente a los perjuicios causados como parte de un grupo.

Este trabajo ha tenido como principal objeto determinar si es que la figura del incremento material del riesgo podría aplicarse en el Derecho peruano. Como he intentado explicar en las líneas precedentes, considero que los jueces y árbitros en el Perú cuentan con herramientas suficientes para aplicar la Excepción del Individuo Indeterminado al amparo de la teoría de la causalidad adecuada, aunque - para evitar resultados no deseados y en atención a las lecciones que nos deja la jurisprudencia anglosajona- deben ser cautelosos en su empleo y deben cuidar que en cada caso estén presentes todos los elementos y requisitos que permiten su uso prudente.

A raíz de lo anterior, y en un contexto en donde constantemente se está revisando oportunidades de mejora en el Código Civil peruano, podría considerarse incorporar en él una disposición que expresamente permita a la víctima obtener la correspondiente indemnización ante el vacío probatorio que intenta solucionar la Excepción del Individuo Indeterminado. Ejemplos de normas para dicho fin se encuentran en diversos códigos civiles, como el alemán, el holandés y el argentino. No obstante, corresponderá a los legisladores encontrar un balance entre la protección de la víctima ante el referido vacío probatorio - como lo hacen el código alemán y holandés-y la indefensión de los presuntos autores; debiendo procurar, por ejemplo, no invertir la carga de la prueba en materia de causalidad, puesto que ello tan solo oculta el problema subyacente, conforme la experiencia internacional lo demuestra. 